\title{
Synchronous tropical and polar temperature evolution in the Eocene
}

\author{
Margot J. Cramwinckel ${ }^{1 *}$, Matthew Huber ${ }^{2}$, Ilja J. Kocken ${ }^{1}$, Claudia Agnini ${ }^{3}$, Peter K. Bijl ${ }^{1}$, Steven M. Bohaty ${ }^{4}$, Joost Frieling ${ }^{1}$, \\ Aaron Goldner ${ }^{2}$, Frederik J. Hilgen ${ }^{1}$, Elizabeth L. Kip ${ }^{1}$, Francien Peterse ${ }^{1}$, Robin van der Ploeg ${ }^{1}$, Ursula Röhl ${ }^{5}$, \\ Stefan Schouten ${ }^{1,6} \&$ Appy Sluijs ${ }^{1}$
}

Palaeoclimate reconstructions of periods with warm climates and high atmospheric $\mathrm{CO}_{2}$ concentrations are crucial for developing better projections of future climate change. Deep-ocean ${ }^{1,2}$ and high-latitude ${ }^{3}$ palaeotemperature proxies demonstrate that the Eocene epoch (56 to 34 million years ago) encompasses the warmest interval of the past 66 million years, followed by cooling towards the eventual establishment of ice caps on Antarctica. Eocene polar warmth is well established, so the main obstacle in quantifying the evolution of key climate parameters, such as global average temperature change and its polar amplification, is the lack of continuous high-quality tropical temperature reconstructions. Here we present a continuous Eocene equatorial sea surface temperature record, based on biomarker palaeothermometry applied on Atlantic Ocean sediments. We combine this record with the sparse existing data $^{4-6}$ to construct a 26-million-year multi-proxy, multi-site stack of Eocene tropical climate evolution. We find that tropical and deep-ocean temperatures changed in parallel, under the influence of both long-term climate trends and short-lived events. This is consistent with the hypothesis that greenhouse gas forcing ${ }^{7,8}$, rather than changes in ocean circulation ${ }^{9,10}$, was the main driver of Eocene climate. Moreover, we observe a strong linear relationship between tropical and deep-ocean temperatures, which implies a constant polar amplification factor throughout the generally icefree Eocene. Quantitative comparison with fully coupled climate model simulations indicates that global average temperatures were about 29, 26, 23 and 19 degrees Celsius in the early, early middle, late middle and late Eocene, respectively, compared to the preindustrial temperature of 14.4 degrees Celsius. Finally, combining proxy- and model-based temperature estimates with available $\mathrm{CO}_{2}$ reconstructions ${ }^{8}$ yields estimates of an Eocene Earth system sensitivity of 0.9 to 2.3 kelvin per watt per square metre at 68 per cent probability, consistent with the high end of previous estimates $^{11}$.

It is well established that deep-ocean temperatures peaked during the Early Eocene Climatic Optimum (EECO; about 52-50 million years (Myr) ago) and had declined substantially by the latest Eocene (about $34 \mathrm{Myr}$ ago $)^{1,2}$. These trends are mimicked in reconstructions of sea surface temperature (SST) in the southern high latitudes ${ }^{3}$ because Eocene deep-ocean temperatures reflect Southern Ocean winter surface conditions that are relayed to the abyss through deep-water formation ${ }^{12}$. However, to unlock the unique promise of Eocene palaeoclimate records to answer fundamental questions about the relationship between atmospheric $\mathrm{CO}_{2}$ concentrations and global temperature, and to quantify the polar amplification of climate change, accurate reconstructions of tropical surface oceans are required. Moreover, tropical records are necessary to test the two competing hypotheses for Eocene deep-ocean and polar cooling: (1) decreasing greenhouse gas concentrations, predominantly $\mathrm{CO}_{2}$ (refs ${ }^{7,8}$ ), and (2) changes in ocean circulation and meridional heat transport associated with opening of ocean gateways ${ }^{9,10}$. In theory, gateway opening cools the Southern Ocean and deep ocean while warming the upper tropical ocean by a few degrees ${ }^{13}$, whereas $\mathrm{CO}_{2}$ decline leads to global cooling at both the Equator and the poles ${ }^{14}$-albeit with predicted amplified polar temperature change relative to the tropics ${ }^{15}$. Importantly, this amplification factor affects the volume and extent of ice sheets, and thus the global sea level, and is therefore critical to constrain, also for future projections. Yet, despite evidence for $\mathrm{CO}_{2}$ decline over the Eocene ${ }^{8}$, existing tropical records ${ }^{4-6}$ are fragmentary and of low resolution, and therefore insufficient to address these crucial questions.

We generated new temperature reconstructions using a clay-bearing, micritic porcellanite sequence recovered at Ocean Drilling Program (ODP) Site 959 in the eastern equatorial Atlantic Ocean (Fig. 1). Site 959 was positioned at near-equatorial latitudes and deep-bathyal water depths throughout the Eocene ${ }^{16}$ (Extended Data Table 1a). We augment the existing age mode ${ }^{16}$ with new biostratigraphic and chemostratigraphic constraints (Extended Data Table 1b, Extended Data Fig. 1). Although carbonate preservation is poor ${ }^{16}$, well preserved, immature organic matter is present throughout ${ }^{17}$. We therefore employ the organic $\mathrm{TEX}_{86}$ palaeothermometer, which utilizes the temperaturedependent distribution of thaumarchaeotal membrane lipids to reconstruct SST. Fractional abundances of the various lipids at Site 959 indicate an upper water column (50-300 m) source (Methods), which allows confident SST interpretations from $\mathrm{TEX}_{86}$. Several calibrations exist to translate $\mathrm{TEX}_{86}$ data into SSTs on the basis of a modern core-top

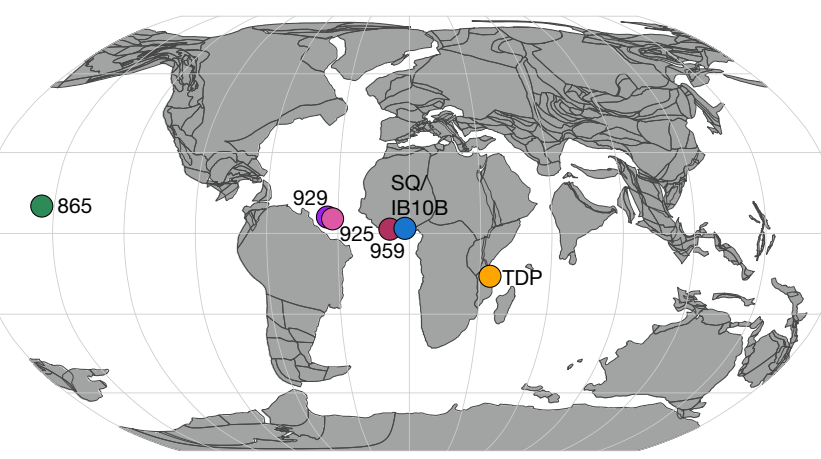

Fig. 1 | Palaeogeographic reconstruction of the studied sites 40 million years ago. The figure shows the approximate palaeoposition of the studied site (ODP Site 959) and the main sites that we used to produce a tropical SST compilation: ODP sites 865, 925 and 929; Tanzania Drilling Project (TDP); Sagamu Quarry (SQ) and IB10B Core, Nigeria. Continental plates are shown in dark grey. Light-grey gridlines represent latitudes and longitudes, with $30^{\circ}$ spacing. The map was generated with GPlates, using the rotation frame and tectonic reconstruction of Matthews et al..$^{30}$.

\footnotetext{
${ }^{1}$ Department of Earth Sciences, Faculty of Geoscience, Utrecht University, Utrecht, The Netherlands. ${ }^{2}$ Department of Earth, Atmospheric, and Planetary Sciences, Purdue University, West Lafayette, IN, USA. ${ }^{3}$ Department of Geosciences, University of Padova, Padova, Italy. ${ }^{4}$ Ocean and Earth Science, National Oceanography Centre Southampton, University of Southampton, Southampton, UK. ${ }^{5}$ MARUM - Center for Marine Environmental Sciences, University of Bremen, Bremen, Germany. ${ }^{6}$ NIOZ Royal Netherlands Institute for Sea Research, Department of Marine Microbiology and Biogeochemistry and Utrecht University, Den Burg, The Netherlands. *e-mail: m.j.cramwinckel@uu.nl
} 


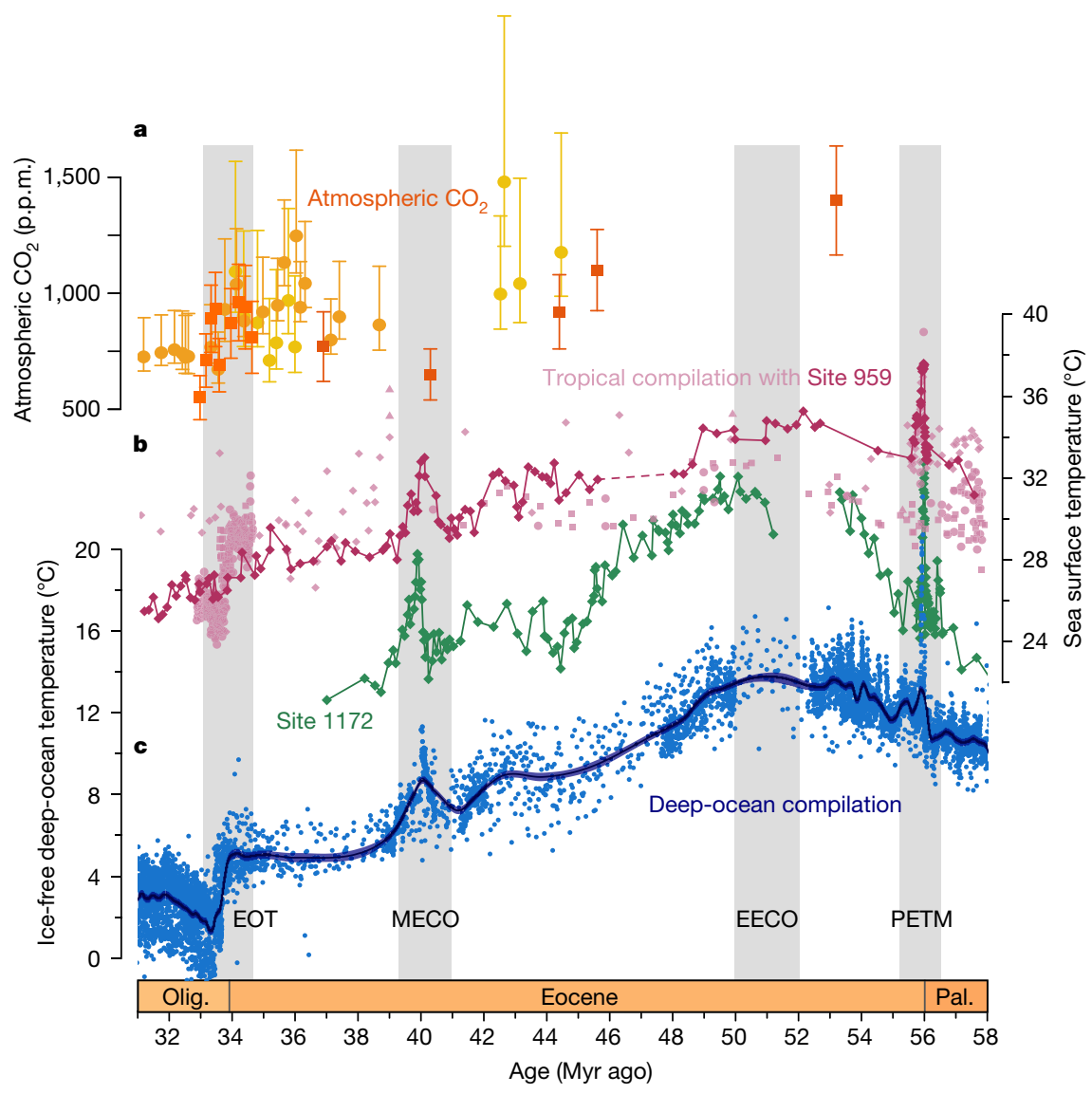

Fig. 2 Eocene global climate evolution. a, $\mathrm{CO}_{2}$ record from boron isotopes from the TDP (orange squares; error bars represent $68 \%$ confidence intervals) and alkenones from ODP Sites 612 and 925 (yellow and orange circles; uncertainties from original studies); data sources are provided in Methods. b, TEX H6 $^{\mathrm{H}}$-based SST record for Site 959 (red) and additional tropical compilation (pink; see Extended Data Fig. 5). The dashed line represents a hiatus. Green diamonds (Site 1172) show a highlatitude $\mathrm{TEX}_{86}^{\mathrm{H}}$-based SST record ${ }^{3} . \mathbf{c}$, $\delta^{18} \mathrm{O}$-based ice-free deep-ocean temperature (described in Methods), with fitted LOESS model (black line) and 95\% confidence interval (dark-blue shading). Age follows the Geologic Time Scale 2012 (GTS2012). Pal., Palaeocene; Olig., Oligocene; EOT, Eocene-Oligocene transition. datase $^{18}$. For biophysical and analytical reasons, we prefer conservative estimates of tropical temperature generated by the logarithmic $\mathrm{TEX}_{86}^{\mathrm{H}}$ calibration $^{18}$ (Methods, Extended Data Fig. 2). In addition, we use a linear Bayesian spatially varying regression (BAYSPAR) calibration ${ }^{19}$ as complementary analysis (Extended Data Fig. 3).

Our new equatorial record from Site 959 (Fig. 2) shows latest-Palaeocene (about $58-56 \mathrm{Myr}$ ago) SSTs of $31-33^{\circ} \mathrm{C}$, mimicking time-equivalent SSTs derived from glassy preserved planktonic foraminiferal oxygen isotope $\left(\delta^{18} \mathrm{O}\right)$ and $\mathrm{Mg} / \mathrm{Ca}$ ratios, as well as $\mathrm{TEX}_{86}^{\mathrm{H}}$ data from a nearby section in Nigeria ${ }^{20}$ - supporting the notion that $\mathrm{TEX}_{86}^{\mathrm{H}}$ accurately reflects SST at Site 959 . The record further reveals warming by $2-3^{\circ} \mathrm{C}$ from the latest Palaeocene to the earliest Eocene ( 58 to $53 \mathrm{Myr}$ ago) to peak EECO temperatures of $34-35^{\circ} \mathrm{C}$. Superimposed transient warming of around $4{ }^{\circ} \mathrm{C}$ to around $37^{\circ} \mathrm{C}$ occurred during the PalaeoceneEocene Thermal Maximum (PETM), about $56 \mathrm{Myr} \mathrm{ago}^{21}$. A long-term SST drop of about $7{ }^{\circ} \mathrm{C}$ to about $28^{\circ} \mathrm{C}$ characterizes the interval from the middle to late Eocene, and an additional cooling by around $2^{\circ} \mathrm{C}$ to around $26^{\circ} \mathrm{C}$ marks the Eocene-Oligocene transition (about $34 \mathrm{Myr}$ ago). Superimposed on long-term cooling is the first tropical SST reconstruction of the Middle Eocene Climatic Optimum ${ }^{22}$ (MECO), at roughly $40 \mathrm{Myr}$ ago, displaying warming by around $4^{\circ} \mathrm{C}$ from background temperatures to a peak of about $33^{\circ} \mathrm{C}$. This provides compelling evidence that the MECO was associated with global warming; surface warming was previously only recognized in extratropical regions of the Southern Hemisphere. We also record pre-MECO temperature variability of similar duration but lower amplitude.

To assess whether regional upwelling ${ }^{17}$ at Site 959 influenced $\mathrm{TEX}_{86^{-}}$ based SST variability, we consider published total organic carbon
(TOC) contents ${ }^{17}$ of sediments and generate dinocyst assemblage data, as dinocysts are highly sensitive to upwelling in modern and Palaeogene oceans ${ }^{23}$ (Extended Data Fig. 4). The continuous presence of cysts of Protoperidiniaceae (derived from heterotrophic dinoflagellates) and elevated TOC within biosiliceous sediments ${ }^{16}$ indicate upwelling throughout the middle and late Eocene. The early Eocene is less well constrained, but presence of Protoperidiniaceae and abundant biosilica also suggests upwelling. An upper-Eocene increase in TOC content ${ }^{17}$ might indicate upwelling intensification. Although this may exaggerate latest-Eocene cooling at Site 959, the recorded magnitude (about $2^{\circ} \mathrm{C}$ ) is similar to previous work at tropical locations ${ }^{24}$ (Fig. 2). Apart from the late Eocene, however, variations in our SST record are not strongly correlated to changes in the abundance of upwellingindicative dinocysts or TOC content. Regional upwelling may have muted SSTs by a few degrees. Indeed, our values are somewhat lower than the few time-equivalent data points from the warm pool sampled in Tanzania ${ }^{4}$, suggesting that we sampled the first Eocene analogue to the 'cold tongue' in the modern ocean. Importantly, this analysis indicates that variations in the strength of upwelling were not a major factor governing SST change at the study site.

We combine our equatorial Site 959 SST record with the available low-resolution data derived from a suite of SST proxies from the Indian, Atlantic and Pacific tropical oceans (Fig. 2; data sources in Extended Data Fig. 5). Because each of these proxies is subject to different systematic sources of error, the close correspondence between various organic and carbonate proxies in both absolute temperatures and trends indicates a robust convergent temperature signal. A local regression (LOESS) model is applied to the resulting compilation to produce an 


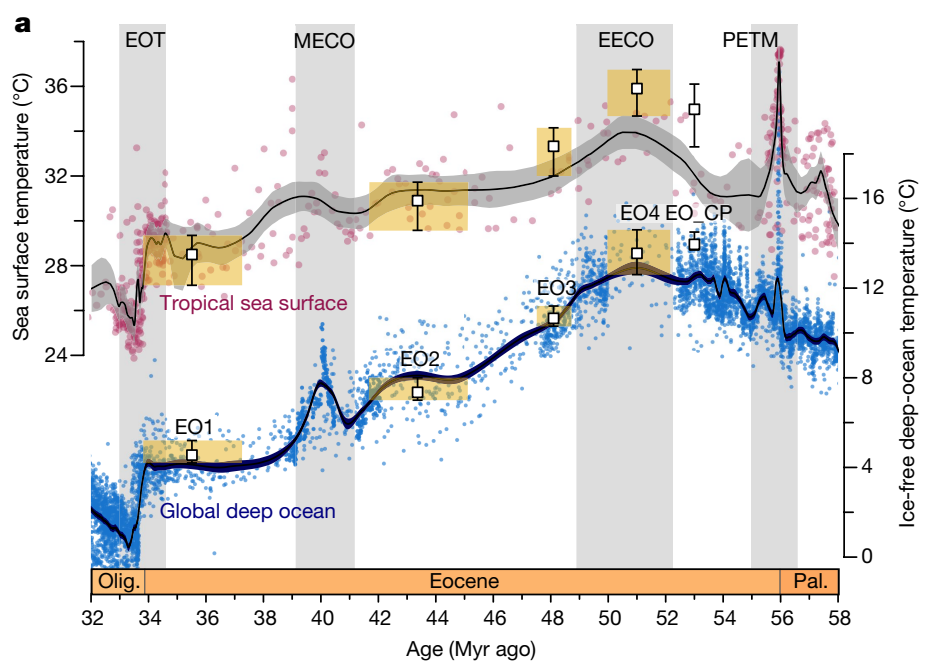

Fig. 3 Proxy-model synthesis of Eocene temperatures. a, Top, tropical SST compilation (red) and LOESS model (black line) with 95\% confidence interval (grey shading). Bottom, deep-ocean temperatures from Fig. 2c. Open squares are mean modelled tropical SSTs and deep-ocean temperatures of simulations EO1 (560 p.p.m. $\mathrm{CO}_{2}$ ), EO2 (1,120 p.p.m. $\mathrm{CO}_{2}$ ), EO3

estimate of Eocene mean tropical temperature (Fig. 3a), yielding $4-7^{\circ} \mathrm{C}$ of cooling through the Eocene. Remarkably, long-term trends and sub-million-year (MECO and PETM) tropical SST variations mimic those from the Southern Ocean and the deep ocean, on the basis of an updated compilation of benthic foraminiferal $\delta^{18} \mathrm{O}$-derived temperatures (Fig. 2). A sensitivity study indicates that potential late Eocene Antarctic ice caps did not appreciably affect this deep-ocean temperature proxy (Methods, Extended Data Fig. 6). The close correspondence between tropical and deep-sea temperatures provides solid proof that greenhouse gas forcing, rather than ocean circulation change, caused Eocene cooling, as has been suggested elsewhere ${ }^{5,7,8}$.

As an approximation of the pole-to-Equator temperature difference, or meridional temperature gradient (MTG), we calculate the difference between tropical mean SST and deep-ocean temperatures (Methods, Fig. 3b). Although different $\mathrm{TEX}_{86}$ calibrations result in slightly different early Eocene MTGs (Extended Data Fig. 3), the gradient generally increases with cooling climate and vice versa, reflecting polar amplification of temperature variability. Remarkably, regression analysis indicates a strong linear relationship between deep-ocean and tropical temperatures (Fig. 4a; also between high-latitude and tropical SSTs in Extended Data Fig. 7). Although uncertainty on the exact value is large owing to uncertainties in temperature proxies and calibrations (Fig. 4b, Extended Data Fig. 3), this signifies a stable polar amplification factor throughout the Eocene. Because the obtained values are consistent with polar amplification derived from an analysis of the PETM event ${ }^{20}$ with better spatial resolution, this observation holds for both short $\left(10^{5}-\mathrm{yr}\right)$ and long (multi-million-year) timescales. In the absence of pronounced snow and ice albedo feedbacks, the polar amplification factor should be determined by atmospheric feedbacks ${ }^{25}$. Therefore, the stable amplification factor implies that the strength of these feedbacks scales linearly with temperature in an ice-free world.

Our temperature proxy compilations provide a concrete and robust test of the ability of models to reproduce past warm climates under increased greenhouse gas forcing. We performed fully coupled general circulation model simulations using the NCAR Community Earth System Model, version 1 (CESM 1), by applying a range of radiative forcings equivalent to a range of Eocene $\mathrm{CO}_{2}$ concentrations -560 parts per million (p.p.m.), 1,120 p.p.m., 2,240 p.p.m. and 4,480 p.p.m.; simulations EO1-EO4, respectively (see Methods) - run to full equilibrium. Because the close correspondence between tropical, high-latitude and deep-sea temperature trends (Fig. 2) supports model-based inferences that Eocene global mean temperature was relatively insensitive b

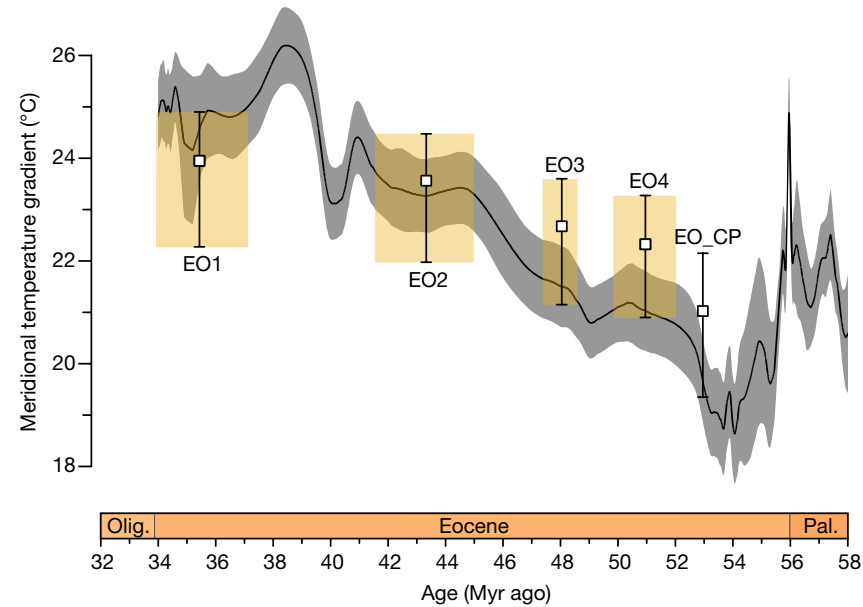

(2,240 p.p.m. $\left.\mathrm{CO}_{2}\right)$, EO4 (4,480 p.p.m. $\left.\mathrm{CO}_{2}\right)$ and EO_CP ${ }^{28}$; errors represent seasonal range. Yellow shadings illustrate age ranges to which the simulations are matched. b. Calculated MTG based on LOESS fits of proxy data (line, propagated 95\% confidence intervals) and model simulations EO1-EO4 and EO_CP (as in a). Age follows GTS2012.

to variations in palaeogeography ${ }^{7,13,26}$, we did not vary the palaeogeographic boundary conditions. The modelled deep waters derive primarily from polar surface waters ${ }^{12}$, justifying our use of the modelled and proxy-derived vertical gradient as an approximation for the MTG. The four simulations, EO1-EO4, were associated with specific age ranges by matching the simulated deep-ocean temperatures to the proxy-based deep-ocean temperatures, thus leaving SST as the predicted variable. Crucially, the simulations closely approximate the multi-proxy, multilocation tropical SST compilation for these four time slices (Fig. 3a). Therefore, the Eocene temperature gradients of $19-26^{\circ} \mathrm{C}$, which are reconstructed from proxies, are also closely reproduced (Fig. $3 \mathrm{~b}$ ). This implies that current-generation climate models are capable of resolving the low-temperature-gradient problem ${ }^{14}$ of Eocene greenhouse climates, provided sufficient greenhouse forcing, albeit with two important exceptions. First, regional proxy-model data mismatches for absolute temperatures in the South Pacific ${ }^{12}$ and Arctic $^{27}$ oceans remain a conundrum, which this study does not resolve. Second, the model simulations do not fully reproduce the most reduced proxy-derived gradients of the early Eocene. On the basis of recent modelling experiments with tuned cloud parameters ${ }^{28}$, one potential explanation could be that the early Eocene hothouse experienced different cloud behaviour and shortwave radiative feedbacks (simulation EO_CP in Fig. 3b). Although a simulation with tuned clouds produces a more reduced early Eocene MTG at lower $\mathrm{CO}_{2}$ concentrations, the same parameters lead to a poorer simulation of the MTG during the PETM ${ }^{28}$ (Extended Data Fig. 8), indicating that this remains an unresolved problem.

With the overall excellent agreement between ocean temperature proxy reconstructions and model simulations, we can use the latter to estimate global mean temperatures, which are required to calculate climate sensitivity to $\mathrm{CO}_{2}$ forcing. Global mean temperatures were about $29^{\circ} \mathrm{C}, 26^{\circ} \mathrm{C}, 23^{\circ} \mathrm{C}$ and $19^{\circ} \mathrm{C}$ during the early (54-49 Myr ago), early middle (48-46 Myr ago), late middle (42-41 Myr ago) and late Eocene (38-35 Myr ago), respectively, compared to a preindustrial temperature of $14.4^{\circ} \mathrm{C}$. These may be slightly underestimated if South Pacific ${ }^{3,12}$ and Arctic ${ }^{27}$ temperature reconstructions represent accurate estimates of annually averaged SST. However, our model requires much larger changes in $\mathrm{CO}_{2}$ to produce the large and dynamic range of Eocene tropical SST and deep-sea temperature than that reconstructed from proxy data ${ }^{8}$. This implies that the Earth system sensitivity ${ }^{11}$ to $\mathrm{CO}_{2}$ doubling derived from the model $\left(3.5^{\circ} \mathrm{C}\right)$ is too low to create sufficient warmth. We consider available Eocene $\mathrm{CO}_{2}$ reconstructions ${ }^{8}$ in combination with our proxy- and model-based temperatures 


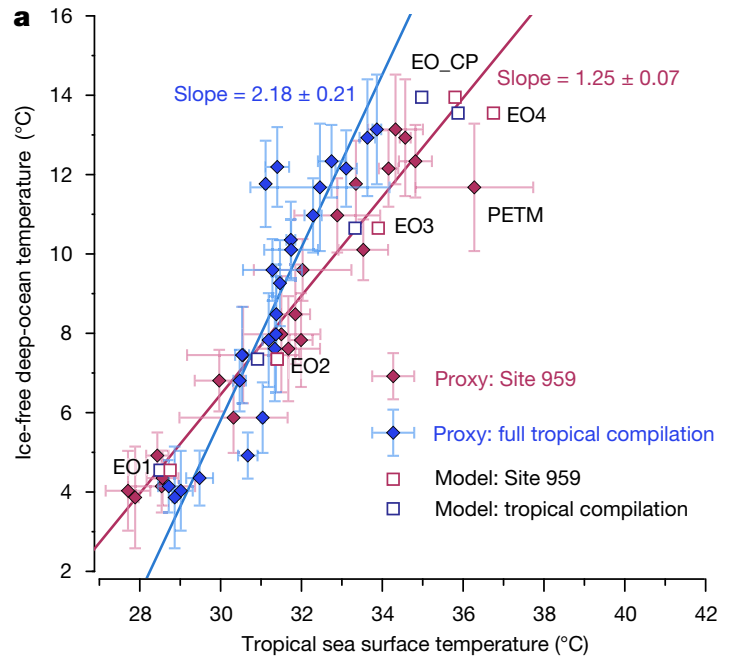

Fig. 4 | Linear relationship between deep-ocean and tropical sea surface temperature. a, Proxy data (58-34 Myr ago, in 1-Myr bins; errors are 1 s.d. due to binning) and model results (open squares are model means for tropical compilation locations) of deep-ocean temperature against tropical SST. Slopes of Deming regressions (lines) represent the polar amplification

(Methods) to estimate the Earth system sensitivity at various parts of the Eocene (Extended Data Fig. 9). Our probabilistic analysis for the cooling between the early and late Eocene results in a calculated proxy-based Earth system sensitivity range of $0.9-2.3 \mathrm{~K} \mathrm{~W}^{-1} \mathrm{~m}^{-2}(68 \%$ highest density interval, equivalent to $3.5-8.9^{\circ} \mathrm{C}$ per $\mathrm{CO}_{2}$ doubling), consistent with the high end of previous estimates ${ }^{11}$.

The large range of Eocene tropical temperatures on both short and long timescales indicates that the tropics respond strongly to changes in greenhouse gases, even at high temperatures. In addition to high absolute temperatures of up to about $35^{\circ} \mathrm{C}$ and $37^{\circ} \mathrm{C}$ during the EECO and $\mathrm{PETM}^{21}$, respectively, this refutes the notion of stable tropical temperatures ${ }^{4}$, kept constant through a physical 'thermostat' mechanism ${ }^{29}$. Moreover, our results show that tropical SST varied in tandem with high-latitude and deep-ocean temperatures, with a stable Eocene polar amplification factor, consistent with a dominant role of $\mathrm{CO}_{2}$ forcing in both long-term Eocene climate evolution and superimposed aberrations including the PETM and MECO. Tropical temperatures are expected to rise in response to anthropogenic greenhouse gas emissions. Given the consistency between our climate simulations and reconstructions, current-generation fully coupled climate models are likely to perform adequately in predicting future tropical SST change, although accurate determination of the sensitivity of global climate to $\mathrm{CO}_{2}$ change remains a major challenge.

\section{Online content}

Any Methods, including any statements of data availability and Nature Research reporting summaries, along with any additional references and Source Data files, are available in the online version of the paper at https://doi.org/10.1038/s41586018-0272-2.

Received: 27 June 2017; Accepted: 13 April 2018;

Published online 2 July 2018.

1. Lear, C. H., Elderfield, H. \& Wilson, P. A. Cenozoic deep-sea temperatures and global ice volumes from $\mathrm{Mg} / \mathrm{Ca}$ in benthic foraminiferal calcite. Science $\mathbf{2 8 7}$, 269-272 (2000)

2. Zachos, J. C., Dickens, G. R. \& Zeebe, R. E. An early Cenozoic perspective on greenhouse warming and carbon-cycle dynamics. Nature 451, 279-283 (2008).

3. Bijl, P. K. et al. Early Palaeogene temperature evolution of the southwest Pacific Ocean. Nature 461, 776-779 (2009).

4. Pearson, P. N. et al. Stable warm tropical climate through the Eocene epoch. Geology 35, 211-214 (2007).

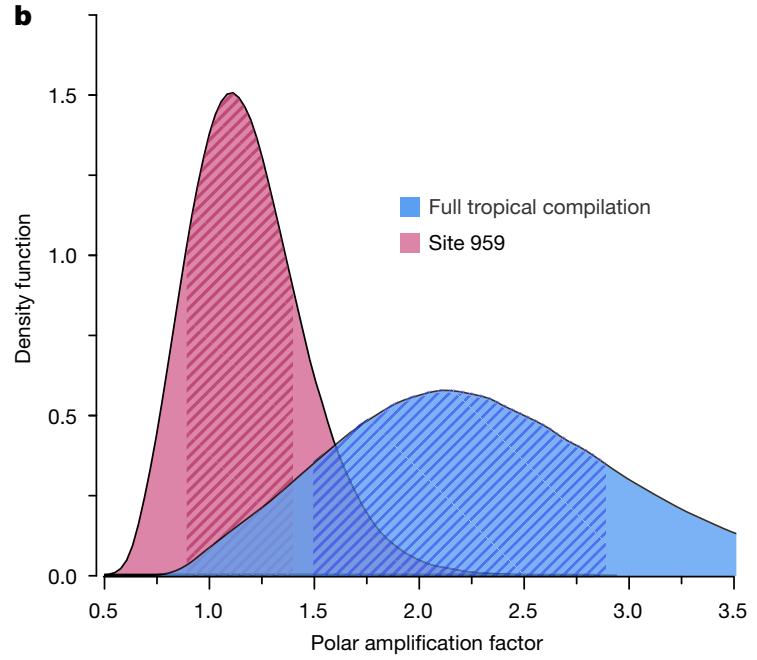

factor ( \pm 1 standard error). The bin 55-56 Myr for Site 959 falls to the right of the regression line because it includes a large amount of PETM event data for Site 959, but less for the deep ocean. b. Density function of polar amplification factor with full propagation of errors (Methods). The hatched regions show the $68 \%$ highest density intervals.

5. Inglis, G. N. et al. Descent toward the Icehouse: Eocene sea surface cooling inferred from GDGT distributions. Paleoceanography 30, 1000-1010 (2015).

6. Evans, D. et al. Eocene greenhouse climate revealed by coupled clumped isotope-Mg/Ca thermometry. Proc. Natl Acad. Sci. USA https://doi. org/10.1073/pnas.1714744115 (2018).

7. Huber, M. et al. Eocene circulation of the Southern Ocean: was Antarctica kept warm by subtropical waters? Paleoceanography 19, PA4026 (2004).

8. Anagnostou, E. et al. Changing atmospheric $\mathrm{CO}_{2}$ concentration was the primary driver of early Cenozoic climate. Nature 533, 380-384 (2016).

9. Kennett, J. P. Cenozoic evolution of Antarctic glaciation, the circum-Antarctic Ocean, and their impact on global paleoceanography. J. Geophys. Res. 82, 3843-3860 (1977).

10. Bijl, P. K. et al. Eocene cooling linked to early flow across the Tasmanian Gateway. Proc. Natl Acad. Sci. USA 110, 9645-9650 (2013).

11. PALAEOSENS Project Members. Making sense of palaeoclimate sensitivity. Nature 491, 683-691 (2012); erratum 494, 130 (2013).

12. Hollis, C. J. et al. Early Paleogene temperature history of the Southwest Pacific Ocean: reconciling proxies and models. Earth Planet. Sci. Lett. 349-350, 53-66 (2012); erratum 374, 258-259 (2013).

13. Sijp, W. P., England, M. H. \& Huber, M. Effect of the deepening of the Tasman Gateway on the global ocean. Paleoceanography 26, PA4207 (2011).

14. Huber, M. \& Caballero, R. The early Eocene equable climate problem revisited. Clim. Past 7, 603-633 (2011).

15. Lunt, D. J. et al. A model-data comparison for a multi-model ensemble of early Eocene atmosphere-ocean simulations: EoMIP. Clim. Past 8, 1717-1736 (2012).

16. Mascle, J. et al. Proceedings of the Ocean Drilling Program Initial Reports Vol. 159 (ODP/TAMU, College Station, 1996).

17. Wagner, T. Late Cretaceous to early Quaternary organic sedimentation in the eastern Equatorial Atlantic. Palaeogeogr. Palaeoclimatol. Palaeoecol. 179, 113-147 (2002).

18. Kim, J.-H. et al. New indices and calibrations derived from the distribution of crenarchaeal isoprenoid tetraether lipids: implications for past sea surface temperature reconstructions. Geochim. Cosmochim. Acta 74, 4639-4654 (2010).

19. Tierney, J. E. \& Tingley, M. P. A. Bayesian, spatially-varying calibration model for the TEX86 proxy. Geochim. Cosmochim. Acta 127, 83-106 (2014).

20. Frieling, J. et al. Extreme warmth and heat-stressed plankton in the tropics during the Paleocene-Eocene Thermal Maximum. Sci. Adv. 3, e1600891 (2017).

21. Frieling, J. et al. Tropical Atlantic climate and ecosystem regime shifts during the Paleocene-Eocene Thermal Maximum. Clim. Past 14, 39-55 (2018).

22. Bohaty, S. M., Zachos, J. C., Florindo, F. \& Delaney, M. L. Coupled greenhouse warming and deep-sea acidification in the middle Eocene. Paleoceanography 24, PA2207 (2009).

23. Sluiijs, A., Pross, J. \& Brinkhuis, H. From greenhouse to icehouse; organicwalled dinoflagellate cysts as paleoenvironmental indicators in the Paleogene. Earth Sci. Rev. 68, 281-315 (2005).

24. Liu, Z. et al. Global cooling during the Eocene-Oligocene climate transition. Science 323, 1187-1190 (2009).

25. Caballero, R. \& Langen, P. L. The dynamic range of poleward energy transport in an atmospheric general circulation model. Geophys. Res. Lett. 32, L02705 (2005). 
26. Goldner, A., Herold, N. \& Huber, M. Antarctic glaciation caused ocean circulation changes at the Eocene-Oligocene transition. Nature 511, 574-577 (2014); erratum 519, 378 (2015)

27. Sluijs, A. et al. Warm and wet conditions in the Arctic region during Eocene Thermal Maximum 2. Nat. Geosci. 2, 777-780 (2009).

28. Kiehl, J. T. \& Shields, C. A. Sensitivity of the Palaeocene-Eocene Thermal Maximum climate to cloud properties. Philos. Trans. R. Soc. A 371, 20130093 (2013).

29. Pierrehumbert, R. T. Thermostats, radiator fins, and the local runaway greenhouse. J. Atmos. Sci. 52, 1784-1806 (1995).

30. Matthews, K. J. et al. Global plate boundary evolution and kinematics since the late Paleozoic. Global Planet. Change 146, 226-250 (2016).

Acknowledgements In this research, we used samples and data provided by the International Ocean Discovery Program (IODP) and its predecessor, the Ocean Drilling Program. This work was carried out under the programme of the Netherlands Earth System Science Centre (NESSC), financially supported by the Dutch Ministry of Education, Culture and Science. A.S. thanks the European Research Council (ERC) for ERC Starting Grant number 259627 under the European Union Seventh Framework Program. This study was made possible by the Netherlands Organisation for Scientific Research (NWO) grant number 834.11.006, which enabled the purchase of the UHPLC-MS system used for GDGT analyses. P.K.B. and F.P. acknowledge NWO-ALW Veni grants number 863.13.002 and number 863.13.016, respectively. M.H. was funded by the US National Science Foundation (NSF) grant OCE-0902882; the CESM model is also supported by the NSF. C.A. acknowledges the University of Padova grant number BIRD161002. We thank B. Wade (University College London) for converting the Eocene TDP data to GTS2012, P. Sexton (The Open University) for converting the middle Eocene Site 1258 data to GTS2012, J. Kiehl and
C. Shields for providing their simulation data, G.-J. Reichart (Royal NIOZ and Utrecht University) for discussions, L. van der Heijden (Utrecht University, now at University of La Rochelle, France), M. Nicolai (Utrecht University), A. Mets (NIOZ), N. Welters, A. van Dijk and D. Kasjaniuk (Utrecht Geolab) for analytical support.

Reviewer information Nature thanks G. Inglis, C. Lear, K. Littler and S. Robinson for their contribution to the peer review of this work.

Author contributions M.J.C., A.S. and M.H. designed the study. M.J.C., F.P., S.S., I.J.K., J.F. and E.L.K. generated and analysed organic geochemical data. M.J.C. A.S., P.K.B., J.F., I.J.K. and E.L.K. generated and analysed palynological data. C.A. generated and analysed nannofossil data. I.J.K., F.J.H., C.A., J.F., R.v.d.P. and M.J.C. developed the age model. M.H. and A.G. performed CESM model simulations All authors contributed to data and model interpretations. M.J.C., A.S. and M.H. wrote the text, with input from all authors.

Competing interests The authors declare no competing interests.

Additional information

Extended data is available for this paper at https://doi.org/10.1038/s41586-

018-0272-2.

Supplementary information is available for this paper at https://doi.

org/10.1038/s41586-018-0272-2.

Reprints and permissions information is available at http://www.nature.com/ reprints.

Correspondence and requests for materials should be addressed to M.J.C.

Publisher's note: Springer Nature remains neutral with regard to jurisdictional claims in published maps and institutional affiliations. 


\section{METHODS}

Palynology. Freeze-dried sediments (96 samples) were crushed and treated with $30 \% \mathrm{HCl}$ and twice with $38 \%-40 \% \mathrm{HF}$ to remove carbonates and silicates, respectively, after a known amount of Lycopodium spores (batch number 1031; 20,848 spores per tablet) was added to enable absolute quantification of palynomorphs. A $15-250 \mu \mathrm{m}$ fraction was isolated using nylon mesh sieves and an ultrasonic bath. No oxidation procedure was applied. An aliquot of homogenized residue was mounted on slides and analysed using light microscopy (400 $\times$ magnification) to a minimum of 200 identified dinocysts.

Organic geochemistry. Lipids were extracted from freeze-dried and powdered sediments (5-25 g dry weight, 118 samples) with dichloromethane (DCM):methanol $(\mathrm{MeOH})(9: 1, \mathrm{v} / \mathrm{v})$ using a Dionex accelerated solvent extractor (ASE 350) at a temperature of $100^{\circ} \mathrm{C}$ and a pressure of $7.6 \times 10^{6} \mathrm{~Pa}$. Lipid extracts were separated into an apolar, ketone and polar fraction by $\mathrm{Al}_{2} \mathrm{O}_{3}$ column chromatography using hexane:DCM (9:1), hexane:DCM (1:1) and DCM:MeOH (1:1) as respective eluents. $99 \mathrm{ng}$ of a synthetic $\mathrm{C}_{46}$ (mass-to-charge ratio, $\mathrm{m} / z=744$ ) glycerol dialkyl glycerol tetraether (GDGT) standard was added to the polar fraction, which subsequently was dissolved in hexane:isopropanol $(99: 1, \mathrm{v} / \mathrm{v})$ to a concentration of $\sim 3 \mathrm{mg} \mathrm{ml}^{-1}$ and passed through a $0.45-\mu \mathrm{m}$ polytetrafluoroethylene filter. This fraction was then analysed by high-performance liquid chromatography (HPLC) and atmospheric pressure chemical ionization-mass spectrometry using an Agilent 1260 Infinity series HPLC system coupled to an Agilent 6130 single-quadrupole mass spectrometer at Utrecht University following Hopmans et al. ${ }^{31}$ to measure the abundance of GDGTs. The branched and isoprenoid tetraether (BIT) index and $\mathrm{TEX}_{86}$ values were calculated according to Hopmans et al. ${ }^{32}$ and Kim et al. ${ }^{18}$, respectively. Based on long-term observation of the in-house standard, the analytical precision for $\mathrm{TEX}_{86}$ is $\pm 0.3^{\circ} \mathrm{C}$.

GDGT distributions. Of the 118 samples analysed for GDGTs, 5 early Eocene samples did not yield sufficient concentrations of GDGTs to determine TEX $\mathrm{T}_{86}$. Additionally, 4 samples were excluded because either GDGT-2 (2 samples) or crenarchaeol ( 2 samples) could not be reliably identified. For the remaining 109 samples we evaluated the sources of GDGTs and the reliability of TEX $\mathrm{X}_{86}$. The BIT index ${ }^{32}$, a means of quantifying the relative abundance of soil- and river-derived GDGTs relative to marine GDGTs, is low throughout the entire Eocene (all $<0.25$, with $90 \%$ of values $<0.07$ ) and there is no significant correlation between BIT index and $\operatorname{TEX}_{86}(P>0.3)$. Thus, our TEX $\mathrm{T}_{86}$ values are probably not biased by terrestrial input. Both the methane index and GDGT-2/Cren ratio show normal marine values ( $<0.20$ and $<0.12$, respectively), so there is no indication for high abundance of methanotrophic archaea relative to Thaumarchaeota ${ }^{33,34}$. Furthermore, GDGT-0/Cren is low $(<0.31)$, so there are no indications for enhanced contributions of methanogenic archaea to the pool of isoprenoid GDGTs used in $\mathrm{TEX}_{86}{ }^{35}$. Finally, GDGT-2/GDGT-3 ratios are $<4.5$, ruling out substantial impact of deep-water production of GDGTs ${ }^{36}$. Together, these ratios indicate that GDGT distributions were probably not considerably affected by either GDGT-producing soil bacteria, methanotrophic or methanogenic archaea, or deep-dwelling Thaumarchaeota, thereby designating upper-water-column Thaumarchaeota as the main source and favouring the interpretation of TEX ${ }_{86}^{\mathrm{H}}$ as an SST proxy ${ }^{37}$. Another recently described ratio focuses on the different GDGT distributions produced by modern Thaumarchaeota in the Red Sea ${ }^{5}$. Based on core-top datasets, fractional abundances of Red Sea GDGTs are known to differ from other oceanic settings, notably in containing relatively more crenarchaeol regio-isomer $\left(\mathrm{Cren}^{\prime}\right)^{38}$. This causes a different relationship between $\mathrm{TEX}_{86}$ and SST. Inglis et al. ${ }^{5}$ proposed the $\% \mathrm{GDGT}_{\mathrm{RS}}$, $\left[\mathrm{Cren}^{\prime} /\left(\mathrm{GDGT}-0+\mathrm{Cren}^{\prime}\right)\right] \times 100 \%$, as a means of evaluating whether a 'Red Sea-type' GDGT distribution was present in the geological record. In our tropical Eocene record, $\mathrm{TEX}_{86}$ is strongly driven by fractional abundance of Cren', therefore there is also a strong correlation between $\mathrm{TEX}_{86}$ and \%GDGT $\mathrm{RS}$. However, as Inglis et al. ${ }^{5}$ noted, this Red Sea GDGT distribution cannot be distinguished from a high-temperature $\left(>30^{\circ} \mathrm{C}\right)$ distribution, so \% $\mathrm{GDGT}_{\mathrm{RS}}$ cannot disentangle the effects of high-temperature versus Red Sea-type GDGT distributions at this site. However, we note that the several reasons that have been proposed for the aberrant Red Sea GDGT distribution are not likely to have played a role at Site 959. There is no environmental similarity between Eocene Site 959 and the modern Red Sea that could account for a similarly adapted population of endemic Thaumarchaeota, as the setting is not comparable oceanographically or geomorphologically. Furthermore, our dinocyst record shows no indication of high salinity or strong stratification throughout the record. On this basis, we conclude that there is no reason to assume a similar relationship between $\mathrm{TEX}_{86}$ and SST for Site 959 and the modern Red Sea. Finally, we note that our new equatorial record shows late Palaeocene TEX ${ }_{86}^{\mathrm{H}}$ SST estimates of $31-33^{\circ} \mathrm{C}$, identical to time-equivalent SSTs derived from the $\delta^{18} \mathrm{O}$ and $\mathrm{Mg} / \mathrm{Ca}$ ratios and TEX ${ }_{86}^{\mathrm{H}}$ of glassy preserved Morozovella acuta from nearby sections in Nigeria ${ }^{20}$, confirming accurate proxy-estimated SSTs at the study site.

TEX $_{\mathbf{8 6}}$ calibrations. Calibrations. Different calibrations have been proposed to translate $\mathrm{TEX}_{86}$ into SST. Of note is also a recent paper by Ho and Laepple ${ }^{39}$, who propose that the sedimentary GDGTs derive from the deep ocean and TEX therefore reflects deep $(>500 \mathrm{~m})$ subsurface temperatures rather than SST. However, their conclusions are controversial, as their assumptions are inconsistent with all modern-ocean and microbiological evidence and the statistical method used is questionable ${ }^{40}$. Within the TEX T6 $^{-}$-to-SST calibrations, a first division can be made between calibrations based on core-top samples and those based on mesocosm experiments. Here, we focus on applying different calibrations based on core-top datasets ${ }^{18,41}$, as these implicitly include ecological, water-column and diagenetic effects that are not incorporated in mesocosm experiments. Several linear and nonlinear core-top calibrations have been developed. Of these, the global nonlinear (logarithmic) TEX ${ }_{86}^{\mathrm{H}}$ calibration of Kim et al. ${ }^{18}$ and the BAYSPAR TEX calibration of Tierney and Tingley ${ }^{19,41}$ are particularly applicable and most commonly chosen for higher-temperature settings, such as the Eocene. By treating $\mathrm{TEX}_{86}$ as the dependent variable, BAYSPAR is the only calibration that does not suffer from regression dilution bias. For these calibrations, the differences in absolute temperature and relative temperature change in studies reporting $\mathrm{TEX}_{86}$ values between 0.5 and 0.75 are mostly within the error of the proxy ${ }^{18,19,41}$. Significant differences only appear with $\mathrm{TEX}_{86}$ values above those occurring in modern oceans (that is, $\mathrm{TEX}_{86}>0.73$ ) for which the $\mathrm{TEX}_{86}$-to-SST calibration has to be extrapolated. This is illustrated in Extended Data Fig. 2a, which shows that SST estimates based on the TEX ${ }_{86}^{\mathrm{H}}$ and BAYSPAR calibration for Site 959 are within error between $\mathrm{TEX}_{86}$ values of 0.67 and 0.80 . However, the difference between the calibrations increases at higher $\mathrm{TEX}_{86}$ values. For assessing temperature change in a high temperature setting such as the equatorial Eocene, the choice of calibration therefore becomes an important factor.

Biophysical considerations. For the modern ocean, a linear calibration results in a better statistical correspondence between $\mathrm{TEX}_{86}$ and SST in the temperature range of $5-30^{\circ} \mathrm{C}^{18,42}$. However, the question remains as to whether a linear calibration is the best choice for much warmer Eocene oceans considering the biochemical mechanism underlying the $\mathrm{TEX}_{86}-\mathrm{SST}$ relationship. Hyperthermophilic archaea in culture synthesize an increasing proportion of GDGTs with an increasing number of cyclopentane moieties with increasing temperature ${ }^{43-45}$, probably as a homeoviscous adaptation of the cell membrane ${ }^{46}$. However, the GDGTs included in the TEX $_{86}$ ratio (GDGT1-3 and the crenarchaeol isomer; see equation (1)) constitute a minor part of the membrane lipids of Thaumarchaeota. The dominant GDGTs are GDGT- 0 and crenarchaeol ${ }^{47-49}$. Indeed, in the global core-top dataset, higher crenarchaeol and lower GDGT- 0 are recorded with higher temperatures, although their response is less strong than that of the GDGT isomers included in TEX $\mathrm{X}_{86}$ (Fig. 4 in Kim et al. ${ }^{18}$ ). Thus, $\mathrm{TEX}_{86}$ does not capture the full membrane adaptation of Thaumarchaeota to changing temperatures. Interestingly, the ratio of crenarchaeol/ GDGT- 0 versus TEX $_{86}$ shows a strongly nonlinear relationship in the global coretop data (Extended Data Fig. 2c). This trend is similar to that observed between the $\mathrm{TEX}_{86}$ and the ring index (RI; Extended Data Fig. 2d), which is the average number of cyclopentane rings of GDGTs 0-3, crenarchaeol and its regio-isomer (see equation (2)) and which also shows a strong relationship to temperature ${ }^{50}$.

$$
\begin{aligned}
\mathrm{TEX}_{86} & =\frac{[\mathrm{GDGT}-2]+[\mathrm{GDGT}-3]+\left[\mathrm{Cren}^{\prime}\right]}{[\mathrm{GDGT}-1]+[\mathrm{GDGT}-2]+[\mathrm{GDGT}-3]+\left[\mathrm{Cren}^{\prime}\right]} \\
\mathrm{RI} & =0 \times[\mathrm{GDGT}-0]+1 \times[\mathrm{GDGT}-1]+2 \times[\mathrm{GDGT}-2] \\
& +3 \times[\mathrm{GDGT}-3]+4 \times\left[\text { Cren }+ \text { Cren }^{\prime}\right]
\end{aligned}
$$

In Extended Data Fig. 2c, d the Eocene data from Site 959 overlap the core-top dataset, on both Red Sea and tropical latitude core-top data. This nonlinear relationship indicates that at high temperatures, $\mathrm{TEX}_{86}$ shows a relatively small response to temperature change relative to the amount of crenarchaeol versus GDGT- 0 and RI. This suggests that with increasing temperatures, adaptation of the thaumarchaeotal membrane is increasingly regulated through crenarchaeol and GDGT-0 rather than the GDGTs included in $\mathrm{TEX}_{86}$. This should lead to a flattening of the slope between SST and TEX ${ }_{86}$ and therefore supports a logarithmic relationship. Additional support for this hypothesis comes from recent culturing experiments on three different Thaumarchaeota strains ${ }^{49}$. These show that for two strains, Nitrosopumilus maritimus and strain NAOA6, both TEX ${ }_{86}$ and RI (mainly driven by GDGT- 0 and crenarchaeol) correlate with the incubation temperature. However, in the third strain (NAOA2), RI-but not $\mathrm{TEX}_{86}$-changes with growth temperature. This third strain had the highest growth temperature optimum and the strongest change in RI from $28^{\circ} \mathrm{C}$ to $35^{\circ} \mathrm{C}$. This suggests that at temperatures $>28^{\circ} \mathrm{C}$, membrane adaptation to temperature in certain (hightemperature) Thaumarchaeota may not be well reflected in the $\mathrm{TEX}_{86}$ ratio. It should be noted that no nonlinear response was found in mesocosm experiment $s^{51}$ at temperatures of up to $40^{\circ} \mathrm{C}$. However, this calibration is substantially different from that of the global core-top calibrations owing to the unusually low amounts of the crenarchaeol regio-isomer ${ }^{52}$. A similarly low abundance of the crenarchaeol 
regio-isomer was noted for Nitrosopumilus maritimus and strain NAOA6 ${ }^{49}$. In strain NAOA $2^{49}$, abundances of crenarchaeol regio-isomer were higher and did increase with temperature, suggesting that it may be a better representation for high-temperature-adapted marine Thaumarchaeota. On the basis of the above biophysical evidence, we argue that the slope of the $\mathrm{TEX}_{86}$-to-temperature curve is likely to flatten at temperatures above the surface sediment dataset, such as the $\mathrm{TEX}_{86}$ values recorded in the Eocene of Site 959.

Implications. The use of the nonlinear $\mathrm{TEX}_{86}^{\mathrm{H}}$ calibration results in lower temperature estimates compared to the linear BAYSPAR calibration (Extended Data Fig. 2b) for Site 959 in the early Eocene and late Palaeocene. Notably, for the Palaeocene, such estimates agree better with SSTs derived from glassy preserved planktonic foraminiferal $\delta^{18} \mathrm{O}$ and $\mathrm{Mg} / \mathrm{Ca}$ records from nearby sections in Nigeria $^{20}$. Additionally, the Site $959 \mathrm{TEX}_{86}^{\mathrm{H}}$ estimates fit well with the other SST constraints that we use in our tropical Eocene compilation (Extended Data Fig. 5). Finally, the similarly reduced sensitivity of $\mathrm{TEX}_{86}$ (that is, nonlinearity) at the low end of the temperature range is undisputed because it is apparent in both mesocosm experiments ${ }^{52}$ and in the global core-top dataset ${ }^{18,53}$. We therefore apply the $\mathrm{TEX}_{86}^{\mathrm{H}}$ calibration in our main analysis, which is presented in the main text. Nevertheless, the absolute temperature estimates and magnitude of change obtained from the extrapolated part of the $\mathrm{TEX}_{86}$ calibration curve should always be interpreted with care. For completeness, we also present the results for the MTG and polar amplification analysis using BAYSPAR in Extended Data Fig. 3. This confirms that the use of TEX ${ }_{86}^{\mathrm{H}}$ instead of BAYSPAR gives a conservative estimate of middle late Eocene cooling and MECO warming at Site 959 and thus a low estimate of (early Eocene) MTGs and a maximum estimate of polar amplification compared to BAYSPAR. Crucially, however, the choice of calibration does not affect the trends in tropical surface temperatures (Extended Data Fig. 3a) or the fact that they parallel deep-ocean temperatures, and therefore does not affect our conclusion regarding the drivers of Eocene climate change. The larger Eocene range of tropical temperatures reconstructed using BAYSPAR does imply that SSTs at Site 959 varied more than deep-sea temperatures during the Eocene, suggesting tropical rather than polar amplification. Regardless, the relation between tropical and deepsea temperatures remains linear, reflecting a constant polar amplification factor (Extended Data Fig. 3c).

Age model Site 959. Eocene sediments from Site 959 were too weakly magnetized to yield reliable palaeomagnetic results ${ }^{16}$. Our age model is therefore based on a combination of bio- and chemostratigraphy and supported by cyclic variations in sediment coloration (Extended Data Fig. 1). Although dinoflagellate cyst assemblages support the Eocene age of the analysed material, they do not yield many biostratigraphic events with a well calibrated age in the tropics ${ }^{54}$. A total number of 76 additional standard smear slides (Supplementary Information) were analysed for calcareous nannofossils and enabled the improvement of the initial biostratigraphic framework ${ }^{55}$. Biochronological estimates from the low-latitude nannofossil biozonation ${ }^{56}$ were converted to GTS2012 ${ }^{57}$ using the relative position of each biohorizon within the respective magnetochron. In total, 10 robust nannofossil tie-points were used (Extended Data Table 1). The base and top of Chiasmolithus gigas could not be used at this site owing to the extremely low abundance of this species. Therefore, alternative biohorizons in the evolutionary lineage Sphenolithus furcatolithoides morph. A-Sphenolithus cuniculus-S. furcatolithoides morph. B were used. On the basis of the co-occurrence of two non-synchronous bio-events (base Nannotetrina alata gr. and base Nannotetrina cristata) at the same depth (between 740.95 and 741.63 metres below sea floor (mbsf)) and supported by a sudden shift in the nannofossil assemblage, the presence of a hiatus was inferred in Core 35R at $\sim 741$ mbsf. The presence of Nannotetrina alata sensu strico in combination with Sphenolithus perpendicularis and transitional forms of sphenoliths at $740.95 \mathrm{mbsf}$ suggests that the sediments just above the hiatus are very close in age to the actual base of the N. alata group. Therefore, we also include this biohorizon in our age model. The lower boundary of the hiatus is based on linear extrapolation of the underlying sedimentation rate of $1.27 \mathrm{~cm} \mathrm{kyr}^{-1}$. This approach results in a hiatus of 1.5 Myr (48.0-46.5 Myr ago). To further constrain the age model, several chemostratigraphic tie-points were used. The onset of the carbon isotope excursion marking the Palaeocene-Eocene thermal maximum ( $\sim 56 \mathrm{Myr}$ ago) was recently identified ${ }^{21}$ at $804.09 \mathrm{mbsf}$. In addition, the previously identified late Eocene minimum in osmium isotope ratios ${ }^{58}\left({ }^{187} \mathrm{Os} /{ }^{188} \mathrm{Os}\right)$ at $458.65 \mathrm{mbsf}$ has an age of 34.4 Myr ago in GTS2012 on the basis of the correlation to the Os isotope record at the well dated ODP sites 1218 and $1219^{59}$. These age constraints indicate that our data span the entire Eocene. The age model is further supported by calculated sedimentation rates from selected intervals, where high-resolution colour logs showed more than four easily distinguishable cycles. Sedimentation rates were calculated by assuming that these smallest-scale alternations are precession-forced, and were thus assigned a duration of $21 \mathrm{kyr}$ per cycle. These sedimentation rates (blue lines in Extended Data Fig. 1) correspond closely to those based on chemostratigraphy and biostratigraphy. Our age model implies that the warming interval $590-565 \mathrm{mbsf}$ reflects the MECO, which is further supported by a shift in osmium isotope ratios that was also identified within the MECO at sites 1263 and $\mathrm{U} 1333^{60}$. Owing to a lack of nannofossils in the poorly recovered upper part of Hole 959D, linear extrapolation was used for the data points below $466 \mathrm{mbsf}$. This places the Eocene-Oligocene boundary at $447.5 \mathrm{mbsf}$, which is in good agreement with the placing of the Oil glacial event on the basis of osmium isotope recovery after the minimum of 34.4 Myr ago by Ravizza and Paquay ${ }^{58}$.

Age models other sites. ODP Site 1172 . The $\mathrm{TEX}_{86}$-based SST record from Site $1172^{3,61,62}$ is plotted (Fig. 2) on an age model based on the magnetostratigraphy of Bijl et al..$^{63}$, which is in turn largely grounded on the original interpretation by Fuller and Touchard ${ }^{64}$. This was supplemented with three well-calibrated dinocyst events from Dallanave et al. ${ }^{65}$ (top and base Charlesdowniea edwardsii and top Wilsonidium ornatum) instead of the uncertain magnetochron reversals for this interval (552-578 mbsf).

Dahomey Basin, Nigeria. For the Sagamu Quarry and IB10B Core, Nigeria, published biostratigraphic and chemostratigraphic age constraint ${ }^{20}$ were used. Specifically, base Morozovella subbotinae and base Acarinina soldadoensis were used for the Sagamu Quarry (SQ) and base Acarinina soldadoensis, top Morozovella acuta, carbon isotope excursion (CIE) onset and top CIE recovery were used for IB10B as age-depth tie-points.

Tropical SST compilation. For the presented compilation, we integrate the new ODP Site 959 TEX $_{86}$-based SST record with several existing SST proxy records, specifically $\delta^{18} \mathrm{O}$ of photosymbiont-bearing planktonic foraminifera Morozovella spp. (upper mixed layer) and Acarinina spp. (mixed layer) from the SQ, Nigeria ${ }^{20}$ and TDP sections $s^{4,66}$ and near-surface dwelling Turborotalia ampliapertura from $\mathrm{TDP}^{67} ; \mathrm{Mg} / \mathrm{Ca}$ of Morozovella spp. from ODP Site $865^{68}$ and SQ ${ }^{20}$, Acarinina spp. from $\mathrm{SQ}^{20}$ and T. ampliapertura from $\mathrm{TDP}^{69} ; \mathrm{TEX}_{86}$ from ODP Site $925^{24,70}$, Site $929^{5,24}, \mathrm{TDP}^{4}$, SQ and the IB10B Core, Nigeria ${ }^{20}$; and clumped isotope $\left(\Delta_{47}\right)$ thermometry of shallow-dwelling large benthic foraminifera from Evans et al. ${ }^{6}$ (Supplementary Information). We did not include data from South Dover Bridge ${ }^{5}$ and Walvis Ridge ${ }^{71}$ because plate tectonic reconstructions place them outside the $30^{\circ} \mathrm{N}-30^{\circ} \mathrm{S}$ latitude band. Age models for all sites were converted to GTS2012 using published age-depth tie-points. For the $\mathrm{Mg} / \mathrm{Ca}$ proxy, (normalized) $\mathrm{Mg} / \mathrm{Ca}$ compositions were converted to SST using the calibration from Anand et al. ${ }^{72}$ and the Eocene seawater $\mathrm{Mg} / \mathrm{Ca}$ reconstruction from Evans et al. ${ }^{6}$, and using ${ }^{73} \mathrm{H}=0.42$ to correct for the power-law dependence of test $\mathrm{Mg} / \mathrm{Ca}$ values on changing seawater $\mathrm{Mg} / \mathrm{Ca}$ ratios ${ }^{74}$. Conversion of $\delta^{18} \mathrm{O}$ to temperature was done following Erez and $\mathrm{Luz}^{75}$, assuming a constant ice-free global $\delta^{18} \mathrm{O}_{s w}$ of $-1.2 \% \mathrm{VPDB}^{76}$ (Vienna Pee Dee belemnite) and (constant) latitudinal corrections for TDP and SQ of $0.83 \%$ and $0.61 \%$, respectively ${ }^{77}$. $\mathrm{A}+2{ }^{\circ} \mathrm{C}$ correction to convert reconstructed T. ampliapertura temperatures to SST (as used in the original publication ${ }^{69}$ ) was omitted here. It should be noted that different seawater chemistry assumptions for the $\delta^{18} \mathrm{O}$ and $\mathrm{Mg} / \mathrm{Ca}$ proxies may result in shifts in reconstructed temperatures, but do not qualitatively change trends or the correspondence between trends. Multiple measured specimens per sample in the original studies have been averaged into one value for this compilation. For the $\mathrm{TEX}_{86}$-based records, samples with aberrant GDGT ratios were removed following Inglis et al. ${ }^{5}$. The logarithmic $\mathrm{TEX}_{86}^{\mathrm{H}}$ calibration of Kim et al. ${ }^{18}$ is presented in the main text and a full supplementary analysis using the linear BAYSPAR ${ }^{19}$ calibration is provided. For the BAYSPAR calibration, the default search tolerance (2 standard deviations of the raw TEX $_{86}$ dataset) was used for Site 959, 925 and 929 , which yields a representative set of low-latitude calibration localities. The search tolerance was stretched to 0.15 TEX units for the Dahomey Basin and TDP records, in order to not only sample the possibly anomalous modern Red $\mathrm{Sea}^{38}$, but also include a broad representative sample of low-latitude localities.

Global deep-ocean temperature compilation. We base our deep-ocean temperature compilation on the benthic isotope stack previously compiled by Zachos et al. ${ }^{2}$ and supplement this with several high-resolution benthic isotope records, specifically from ODP Site $690^{78,79}$, ODP Site $748^{22}$, ODP Site $1218^{80}$, ODP Site $1209^{81}$, ODP Site $1258^{82}$, ODP Site $1262^{83}$ and ODP Site $1263^{84}$. After the respective species-specific corrections for disequilibrium vital effects ${ }^{85}$ were applied, $\delta^{18} \mathrm{O}$-to-temperature conversion was done following Erez and $\mathrm{Luz}^{75}$, assuming a constant ice-free global $\delta^{18} \mathrm{O}_{\mathrm{sw}}$ of $-1.2 \% \mathrm{VPDB}^{76}$. Age models for all sites were converted to GTS2012 using published age-depth tie-points.

$\mathrm{CO}_{2}$ compilation. The compiled $\mathrm{CO}_{2}$ record plotted in Fig. 2 derives from boron isotopes from TDP ${ }^{8,86}$, with $68 \%$ confidence intervals, as reported in Foster et al. ${ }^{87}$, and alkenones from ODP Site $612^{88}$ and Site $925^{70}$.

Meridional temperature gradients. As an approximation for the pole-to-Equator temperature difference or MTG, we calculate the difference between tropical mean SST and deep-ocean temperatures. The latter are better constrained than high-latitude SSTs and exclude potential summer temperature biases that might plague available high-latitude SST records. We use deep-ocean temperatures based on $\delta^{18} \mathrm{O}$, as these are better constrained than those based on $\mathrm{Mg} / \mathrm{Ca}$, particularly because of the large uncertainties regarding seawater $\mathrm{Mg} / \mathrm{Ca}$ values as well as larger uncertainty between different calibrations and corrections used to convert 
$\mathrm{Mg} / \mathrm{Ca}$ to temperature. We note that our approach of using the LOESS-fitted data provides robust estimates of long-term changes in MTG, but is less appropriate for considering transient events, as fitted event MTGs (for example, for the PETM and MECO) are very dependent on the bandwidth of the fit and the specific records used (Extended Data Fig. 8).

Sensitivity to late Eocene ice volume. The Cenozoic benthic foraminiferal $\delta^{18} \mathrm{O}$ signal reflects both deep-water temperature and global ice volume changes. Although it is unlikely that large Antarctic ice sheets were present in the warmest interval of the Cenozoic during the early Eocene, the extent of middle late Eocene Antarctic glaciation is more uncertain (see, for example, Miller et al. ${ }^{89}$, Barker et al. ${ }^{90}$ and Gasson et al. ${ }^{91}$ ). Recent work argues for possible early middle Eocene glaciation ${ }^{92}$ but the dating of these sediments is highly uncertain. Although there might be evidence for glacial activity, the interpreted presence of large East Antarctic ice sheets in the early middle Eocene is highly controversial, certainly in light of very warm temperatures on the East Antarctic margin ${ }^{93}$. Nevertheless, initial small ice caps in the middle late Eocene would have had relatively enriched isotopic compositions of $-20 \%$ to $-35 \%$. VSMOW ${ }^{94}$ (Vienna Standard Mean Ocean Water) relative to mean modern Antarctic ice ( $-54 \%$ VSMOW). We assess the effect of a range of middle late Eocene ice volumes with different isotopic compositions on the mean $\delta^{18} \mathrm{O}$ of Eocene seawater (Extended Data Fig. 6d). This demonstrates that the effect of ice volume was probably not more than $\sim 0.25 \%$, or $\sim 1^{\circ} \mathrm{C}$, in the latest Eocene. To further illustrate this, we present both the record of ice-free deep-ocean temperature evolution and a second line based on a linear build-up of late Eocene ice volume from $39.5 \mathrm{Myr}$ ago (post-MECO) onwards to a latest-Eocene (34.0 Myr ago) maximum of $10^{7} \mathrm{~km}^{3}\left(\mathrm{refs}^{95,96}\right)$ with an isotopic composition of $-25 \%$ VSMOW $^{94}$ (Extended Data Fig. 6a). This makes a maximum difference of about $0.8^{\circ} \mathrm{C}\left(\Delta \delta^{18} \mathrm{O}_{\text {sw }}\right.$ of $\left.0.18 \%\right)$ in the latest Eocene. We further propagate this uncertainty into the analysis of MTGs and polar amplification factors (Extended Data Fig. 6b, c).

CESM 1 model simulations. The CESM 1 simulations share the same generalized Eocene palaeogeography to assess the effect of changing $\mathrm{CO}_{2}$ by itself, and were all run for more than 3,000 yr to equilibrium. Simulations using an earlier, and generally similar, version of this model were found to produce the best match to early Eocene proxy temperatures within a multi-model ensemble ${ }^{15}$, and preliminary comparison revealed that these new simulations are slightly improved over the earlier version for the early Eocene ${ }^{20}$. Results from the lower- $\mathrm{CO}_{2}$ simulations (560 p.p.m. and 1,120 p.p.m.) and further information on the model can be found in Goldner et al. ${ }^{26}$. This version of CESM has a modern 'fast' climate sensitivity of $2.9^{\circ} \mathrm{C}$ per $\mathrm{CO}_{2}$ doubling ${ }^{97}$ and a nearly constant 'slow' climate sensitivity (ESS) of $3.5^{\circ} \mathrm{C}$ per $\mathrm{CO}_{2}$ doubling in the Eocene simulations used here. For comparison with the proxies in this study, the four simulations with varying $\mathrm{CO}_{2}$ were assigned specific ages by matching the simulated deep-ocean temperatures to the proxy-based deep-ocean temperature reconstruction curve. We then compared the resulting SSTs at the same localities as the main sites in our proxy compilation (ODP sites $865,925 / 929$ and 959 and TDP) and surface-to-deep gradients to evaluate model performance (Supplementary Information). The temperature at the proxy data localities was sampled in a $4^{\circ}$ radius. This approach avoids the circularity of adjusting the climate model radiative forcing to match surface temperature records and provides a target that circumvents the uncertainty introduced by the various errors and uncertainties in surface temperature records. In these simulations, bottom water temperatures in the 4,480 p.p.m. scenario (simulation EO4) are representative of a hot early Eocene climatic optimum extreme (deep-ocean temperature of $13-14^{\circ} \mathrm{C}$, following the conventions of Huber and Caballero ${ }^{14}$ ) whereas the 560 p.p.m. scenario (simulation EO1) is comparable to the latest Eocene (deepocean temperature of $4-5^{\circ} \mathrm{C}$ ), with intermediate simulations (EO2 and EO3) being in between and comparable to the middle Eocene.

Polar amplification factor calculations. First, to obtain an estimate of the factor by which polar temperature change is amplified relative to the tropics (that is, the polar amplification factor), we performed a Deming regression of the Site 959 record against the deep-sea stack of temperatures, accounting for errors in both variables. Data were binned into 1-Myr bins from 34 to $58 \mathrm{Myr}$ ago. We did not include data from the EOT and earliest Oligocene, to exclude major effects of ice volume changes on seawater $\delta^{18} \mathrm{O}$. To assess the robustness of the single regression, we followed a probabilistic approach, using Monte Carlo resampling with full propagation of errors. First, we generated 1,000 iterations of both the tropical SST and deep-ocean temperature datasets. In these iterations, each data point was resampled within the $95 \%$ confidence limits of its propagated analytical plus calibration uncertainty, assuming Gaussian distribution of errors. Using these, we performed 1,000 iterations of a Deming regression of deep-ocean temperature against tropical SST, with data binned into 1-Myr bins from 34 to $58 \mathrm{Myr}$ ago and propagated errors related to the binning used in the regression. We plotted the resulting suite of 1,000 slopes as a probability density function of the polar amplification factor. This exercise was performed using the full tropical temperature compilation and the single Site 959 record. We additionally performed a Deming regression of the Site 959 record against the high-latitude Site 1172 record as a supplementary analysis. The latter analysis generates a similar polar amplification factor, but with larger scatter and uncertainty. This is due to the smaller amount of data points in the Site 1172 SST record relative to the benthic $\delta^{18} \mathrm{O}$ stack, as well as differences in the detailed pattern of Eocene cooling between Site 1172 compared to Site 959 and the deep-ocean temperature record.

ESS calculations. To provide estimates of Eocene ESS sensu Lunt et al. ${ }^{98}$, we combined our proxy and model reconstructions of temperature with the few available $\mathrm{CO}_{2}$ reconstructions based on boron isotopes ${ }^{8}$, involving 1 sample for the early (54-49 Myr ago), 2 samples for the middle (48-42 Myr ago) and 1 sample for the late (38-35 Myr ago) Eocene. We derived temperatures by sampling the proxy compilation within the designated age brackets. We use tropical and deep-ocean temperature change $(\mathrm{d} T)$ as minimum and maximum estimates of $\mathrm{d} T$. Between these, a uniform 'flat' probability distribution was assumed. We converted changes in boron-based $\mathrm{CO}_{2}$ estimates to radiative forcing in $\mathrm{W} \mathrm{m}^{-2}$ using the radiative forcing fit from Byrne and Goldblatt ${ }^{99}$. With the above approach, we derived estimates of ESS in $\mathrm{K} \mathrm{W}^{-1} \mathrm{~m}^{-2}$ for the early Eocene compared to the middle and late Eocene and to the preindustrial temperature. Uncertainties are based on propagated uncertainties of temperature change and radiative forcing derived by resampling these datasets 1,000 times within their $95 \%$ confidence limits (propagated analytical plus calibration uncertainty for temperature, reported $95 \%$ confidence limits from the original work ${ }^{8}$ for $\mathrm{CO}_{2}$ ). In this, we removed radiative forcings $<0$, that is, we assumed that there is no negative forcing associated with increasing $\mathrm{CO}_{2}$. Given the good match between proxies and the presented model simulations, we also calculated ESS using the model-derived global mean temperatures and $\mathrm{CO}_{2}$ proxy data.

Data availability. The data supporting the findings of this study are available within the paper and its Supplementary Information. Original raw data (palynology counts and GDGT concentrations and chromatograms) are available from the corresponding author upon request.

Code availability. The model used in this study is NCAR CESM 1 with CAM4 atmosphere, which is freely available from NCAR (http://www.cesm.ucar.edu/ models/cesm1.0/).

31. Hopmans, E. C., Schouten, S. \& Sinninghe Damsté, J. S. The effect of improved chromatography on GDGT-based palaeoproxies. Org. Geochem. 93, 1-6 (2016).

32. Hopmans, E. C. et al. A novel proxy for terrestrial organic matter in sediments based on branched and isoprenoid tetraether lipids. Earth Planet. Sci. Lett. 224 107-116 (2004).

33. Weijers, J. W. H., Lim, K. L. H., Aquilina, A., Sinninghe Damsté, J. S. \& Pancost, R. D. Biogeochemical controls on glycerol dialkyl glycerol tetraether lipid distributions in sediments characterized by diffusive methane flux. Geochem. Geophys. Geosystems 12, Q10010 (2011).

34. Zhang, Y. G. et al. Methane index: a tetraether archaeal lipid biomarker indicator for detecting the instability of marine gas hydrates. Earth Planet. Sci. Lett. 307, 525-534 (2011)

35. Blaga, C. I., Reichart, G.-J., Heiri, O. \& Damsté, J. S. S. Tetraether membrane lipid distributions in water-column particulate matter and sediments: a study of 47 European lakes along a north-south transect. J. Paleolimnol. 41, 523-540 (2009).

36. Taylor, K. W. R., Huber, M., Hollis, C. J., Hernandez-Sanchez, M. T. \& Pancost, R. D. Re-evaluating modern and Palaeogene GDGT distributions: implications for SST reconstructions. Global Planet. Change 108, 158-174 (2013).

37. Schouten, S., Hopmans, E. C., Schefuß, E. \& Sinninghe Damsté, J. S. Distributional variations in marine crenarchaeotal membrane lipids: a new tool for reconstructing ancient sea water temperatures? Earth Planet. Sci. Lett. 204 265-274 (2002).

38. Trommer, G. et al. Distribution of Crenarchaeota tetraether membrane lipids in surface sediments from the Red Sea. Org. Geochem. 40, 724-731 (2009).

39. Ho, S. L. \& Laepple, T. Flat meridional temperature gradient in the early Eocene in the subsurface rather than surface ocean. Nat. Geosci. 9, 606-610 (2016).

40. Tierney, J. E., Sinninghe Damsté, J. S., Pancost, R. D., Sluijs, A. \& Zachos, J. C. Eocene temperature gradients. Nat. Geosci. 10, 538 (2017).

41. Tierney, J. E. \& Tingley, M. P. A. TEX86 surface sediment database and extended Bayesian calibration. Sci. Data 2, 150029 (2015).

42. Kim, J.-H., Schouten, S., Hopmans, E. C., Donner, B. \& Sinninghe Damsté, J. S. Global sediment core-top calibration of the TEX86 paleothermometer in the ocean. Geochim. Cosmochim. Acta 72, 1154-1173 (2008).

43. De Rosa, M., Gambacorta, A., Nicolaus, B. \& Bu'Lock, J. D. Complex lipids of Caldariella acidophila, a thermoacidophile archaebacterium. Phytochemistry 19, 821-825 (1980).

44. Lai, D., Springstead, J. R. \& Monbouquette, H. G. Effect of growth temperature on ether lipid biochemistry in Archaeoglobus fulgidus. Extremophiles 12, 271-278 (2008)

45. Boyd, E. S. et al. Temperature and pH controls on glycerol dibiphytanyl glycerol tetraether lipid composition in the hyperthermophilic crenarchaeon Acidilobus sulfurireducens. Extremophiles 15, 59-65 (2011).

46. Gliozzi, A., Paoli, G., De Rosa, M. \& Gambacorta, A. Effect of isoprenoid cyclization on the transition temperature of lipids in thermophilic archaebacteria. Biochim. Biophys. Acta 735, 234-242 (1983) 
47. Schouten, S. et al. Intact membrane lipids of "Candidatus Nitrosopumilus maritimus," a cultivated representative of the cosmopolitan mesophilic group crenarchaeota. Appl. Environ. Microbiol. 74, 2433-2440 (2008).

48. Pitcher, A. et al. Core and intact polar glycerol dibiphytanyl glycerol tetraether lipids of ammonia-oxidizing archaea enriched from marine and estuarine sediments. Appl. Environ. Microbiol. 77, 3468-3477 (2011).

49. Elling, F. J., Könneke, M., Mußmann, M., Greve, A. \& Hinrichs, K.-U. Influence of temperature, $\mathrm{pH}$, and salinity on membrane lipid composition and TEX86 of marine planktonic thaumarchaeal isolates. Geochim. Cosmochim. Acta 171, 238-255 (2015).

50. Zhang, Y. G., Pagani, M. \& Wang, Z. Ring Index: a new strategy to evaluate the integrity of TEX86 paleothermometry. Paleoceanography 31, 220-232 (2016).

51. Schouten, S., Forster, A., Panoto, F. E. \& Sinninghe Damsté, J. S. Towards calibration of the TEX86 palaeothermometer for tropical sea surface temperatures in ancient greenhouse worlds. Org. Geochem. 38, 1537-1546 (2007).

52. Wuchter, C., Schouten, S., Coolen, M. J. L. \& Sinninghe Damsté, J. S. Temperature-dependent variation in the distribution of tetraether membrane lipids of marine Crenarchaeota: implications for TEX86 paleothermometry. Paleoceanography 19, PA4028 (2004).

53. Ho, S. L. et al. Appraisal of TEX86 and thermometries in subpolar and polar regions. Geochim. Cosmochim. Acta 131, 213-226 (2014).

54. Awad, W. K. \& Oboh-Ikuenobe, F. E. Early Paleogene dinoflagellate cysts from ODP Hole 959D, Côte d'Ivoire-Ghana Transform Margin, West Africa: new species, biostratigraphy and paleoenvironmental implications. J. Afr. Earth Sci. 123, 123-144 (2016)

55. Shafik, S., Watkins, D. K. \& Shin, I. C. Calcareous nannofossil paleogene biostratigraphy, Côte d'Ivoire-Ghana Marginal Ridge, Eastern Equatorial Atlantic. Proc. Ocean Drill. Program Sci. Results 159, 413-431 (1998).

56. Agnini, C. et al. Biozonation and biochronology of Paleogene calcareous nannofossils from low and middle latitudes. Newsl. Stratigr. 47, 131-181 (2014).

57. Gradstein, F. M., Ogg, J. G., Schmitz, M. D. \& Ogg, G. M. The Geologic Time Scale 2012 (Elsevier, Amsterdam, 2012)

58. Ravizza, G. \& Paquay, F. Os isotope chemostratigraphy applied to organic-rich marine sediments from the Eocene-Oligocene transition on the West African margin (ODP Site 959). Paleoceanography 23, PA2204 (2008).

59. Dalai, T. K., Ravizza, G. E. \& Peucker-Ehrenbrink, B. The late Eocene ${ }^{187}$ Os $/{ }^{188}$ Os excursion: chemostratigraphy, cosmic dust flux and the Early Oligocene glaciation. Earth Planet. Sci. Lett. 241, 477-492 (2006).

60. van der Ploeg, R. et al. Middle Eocene greenhouse warming facilitated by diminished weathering feedback. Nat. Commun. (in the press)

61. Bijl, P. K. et al. Transient middle Eocene atmospheric $\mathrm{CO}_{2}$ and temperature variations. Science 330, 819-821 (2010)

62. Sluijs, $A$. et al. Southern ocean warming, sea level and hydrological change during the Paleocene-Eocene thermal maximum. Clim. Past 7, 47-61 (2011)

63. Bijl, P. K., Sluijs, A. \& Brinkhuis, H. A magneto- and chemostratigraphically calibrated dinoflagellate cyst zonation of the early Palaeogene South Pacific Ocean. Earth Sci. Rev. 124, 1-31 (2013); erratum 134, 160-163 (2014).

64. Fuller, M. \& Touchard, Y. in The Cenozoic Southern Ocean: Tectonics, Sedimentation, and Climate Change Between Australia and Antarctica (eds Exon, N. F. et al.) 63-78 (American Geophysical Union, Washington DC, 2004).

65. Dallanave, E. et al. Constraining early to middle Eocene climate evolution of the southwest Pacific and Southern Ocean. Earth Planet. Sci. Lett. 433, 380-392 (2016).

66. Aze, T. et al. Extreme warming of tropical waters during the Paleocene-Eocene Thermal Maximum. Geology 42, 739-742 (2014).

67. Pearson, P. N. et al. Extinction and environmental change across the EoceneOligocene boundary in Tanzania. Geology 36, 179-182 (2008).

68. Tripati, A. K. et al. Tropical sea-surface temperature reconstruction for the early Paleogene using $\mathrm{Mg} / \mathrm{Ca}$ ratios of planktonic foraminifera. Paleoceanography 18 1101 (2003).

69. Lear, C. H., Bailey, T. R., Pearson, P. N., Coxall, H. K. \& Rosenthal, Y. Cooling and ice growth across the Eocene-Oligocene transition. Geology 36, 251-254 (2008)

70. Zhang, Y. G., Pagani, M., Liu, Z. Bohaty, S. M. \& DeConto, R. A. 40-million-year history of atmospheric CO 2. Philos. Trans. R. Soc. A 371, 20130096 (2013).

71. Boscolo Galazzo, F. et al. The middle Eocene climatic optimum (MECO): a multiproxy record of paleoceanographic changes in the southeast Atlantic (ODP Site 1263, Walvis Ridge). Paleoceanography 29, 1143-1161 (2014).

72. Anand, P., Elderfield, H. \& Conte, M. H. Calibration of Mg/Ca thermometry in planktonic foraminifera from a sediment trap time series. Paleoceanography $\mathbf{1 8 ,}$ 1050 (2003).
73. Hasiuk, F. J. \& Lohmann, K. C. Application of calcite Mg partitioning functions to the reconstruction of paleocean Mg/Ca. Geochim. Cosmochim. Acta 74, 6751-6763 (2010)

74. Evans, D. \& Müller, W. Deep time foraminifera Mg/Ca paleothermometry: nonlinear correction for secular change in seawater $\mathrm{Mg} / \mathrm{Ca}$. Paleoceanography 27, PA4205 (2012)

75. Erez, J. \& Luz, B. Experimental paleotemperature equation for planktonic foraminifera. Geochim. Cosmochim. Acta 47, 1025-1031 (1983).

76. Shackleton, N. J. \& Kennett, J. P. Paleotemperature history of the Cenozoic and the initiation of Antarctic glaciation: oxygen and carbon isotope analyses in DSDP Sites 277, 279 and 281. Initial Rep. Deep Sea Drill. Proj. 29, 743-755 (1975).

77. Zachos, J. C., Stott, L. D. \& Lohmann, K. C. Evolution of Early Cenozoic marine temperatures. Paleoceanography 9, 353-387 (1994).

78. Kennett, J. P. \& Stott, L. D. Abrupt deep-sea warming, palaeoceanographic changes and benthic extinctions at the end of the Palaeocene. Nature 353 225-229 (1991)

79. Thomas, D. J., Zachos, J. C., Bralower, T. J., Thomas, E. \& Bohaty, S. Warming the fuel for the fire: evidence for the thermal dissociation of methane hydrate during the Paleocene-Eocene thermal maximum. Geology 30, 1067-1070 (2002).

80. Coxall, H. K. \& Wilson, P. A. Early Oligocene glaciation and productivity in the eastern equatorial Pacific: insights into global carbon cycling. Paleoceanography 26, PA2221 (2011)

81. Westerhold, T., Röhl, U., Donner, B., McCarren, H. K. \& Zachos, J. C. A complete high-resolution Paleocene benthic stable isotope record for the central Pacific (ODP Site 1209). Paleoceanography 26, PA2216 (2011).

82. Sexton, P. F. et al. Eocene global warming events driven by ventilation of oceanic dissolved organic carbon. Nature 471, 349-352 (2011).

83. Littler, K., Röhl, U., Westerhold, T. \& Zachos, J. C. A high-resolution benthic stable-isotope record for the South Atlantic: implications for orbital-scale changes in Late Paleocene-Early Eocene climate and carbon cycling. Earth Planet. Sci. Lett. 401, 18-30 (2014).

84. Lauretano, V., Hilgen, F. J., Zachos, J. C. \& Lourens, L. J. Astronomically tuned age model for the early Eocene carbon isotope events: a new high-resolution $\delta^{13} \mathrm{C}$ benthic record of ODP Site 1263 between 49 and $\sim 54 \mathrm{Ma}$. Newsl. Stratigr. 49, 383-400 (2016).

85. Shackleton, N. J. \& Hall, M. A. The late Miocene stable isotope record, Site 926. Proc. Ocean Drill. Program, Sci. Results 154, 367-373 (1997).

86. Pearson, P. N., Foster, G. L. \& Wade, B. S. Atmospheric carbon dioxide through the Eocene-Oligocene climate transition. Nature 461, 1110-1113 (2009).

87. Foster, G. L., Royer, D. L. \& Lunt, D. J. Future climate forcing potentially without precedent in the last 420 million years. Nat. Commun. 8, 14845 (2017).

88. Pagani, M., Zachos, J. C., Freeman, K. H., Tipple, B. \& Bohaty, S. Marked decline in atmospheric carbon dioxide concentrations during the Paleogene. Science 309, 600-603 (2005)

89. Miller, K. G., Wright, J. D. \& Browning, J. V. Visions of ice sheets in a greenhouse world. Mar. Geol. 217, 215-231 (2005).

90. Barker, P. F., Diekmann, B. \& Escutia, C. Onset of Cenozoic Antarctic glaciation. Deep Sea Res. Part II Top. Stud. Oceanogr. 54, 2293-2307 (2007).

91. Gasson, E. et al. Exploring uncertainties in the relationship between temperature, ice volume, and sea level over the past 50 million years. Rev. Geophys. 50, RG1005 (2012).

92. Gulick, S. P. S. et al. Initiation and long-term instability of the East Antarctic Ice Sheet. Nature 552, 225-229 (2017).

93. Pross, J. et al. Persistent near-tropical warmth on the Antarctic continent during the early Eocene epoch. Nature 488, 73-77 (2012).

94. DeConto, R. M. et al. Thresholds for Cenozoic bipolar glaciation. Nature 455 652-656 (2008).

95. Gasson, E. et al. Uncertainties in the modelled $\mathrm{CO}_{2}$ threshold for Antarctic glaciation. Clim. Past 10, 451-466 (2014).

96. De Boer, B., van de Wal, R. S. W., Bintanja, R., Lourens, L. J. \& Tuenter, E. Cenozoic global ice-volume and temperature simulations with 1-D ice-sheet models forced by benthic $\delta^{18} 0$ records. Ann. Glaciol. 51, 23-33 (2010).

97. Shields, C. A. et al. The low-resolution CCSM4. J. Clim. 25, 3993-4014 (2012)

98. Lunt, D. J. et al. Earth system sensitivity inferred from Pliocene modelling and data. Nat. Geosci. 3, 60-64 (2010).

99. Byrne, B. \& Goldblatt, C. Radiative forcing at high concentrations of well-mixed greenhouse gases. Geophys. Res. Lett. 41, 152-160 (2014).

100. Torsvik, T. H. et al. Phanerozoic polar wander, palaeogeography and dynamics. Earth Sci. Rev. 114, 325-368 (2012). 


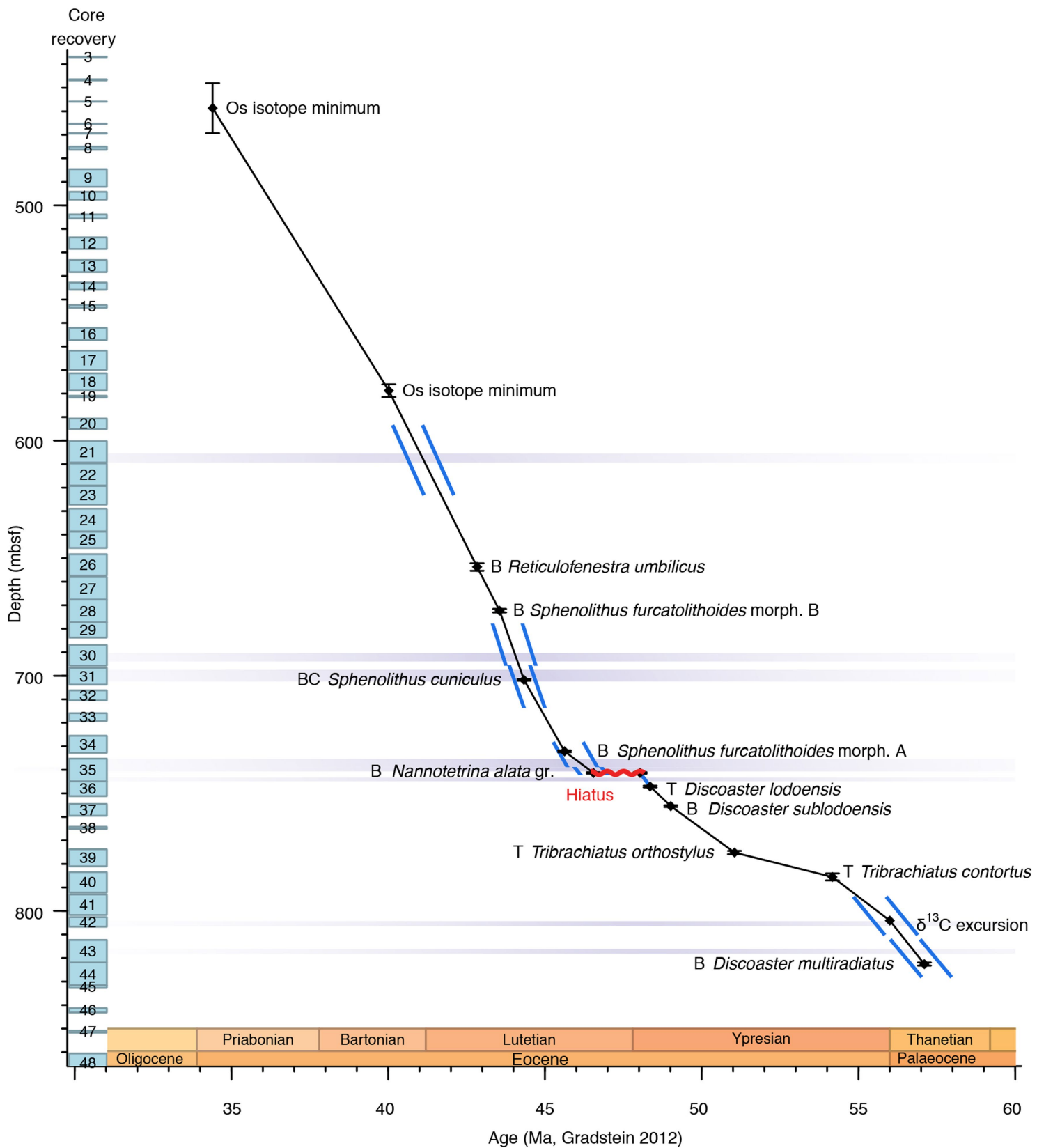

Extended Data Fig. 1 | Augmented age model of Hole 959D. Age-depth plot showing calcareous nannofossil and chemostratigraphic tie-points (diamonds; vertical error bars are indicate the minimum and maximum depth of the tie-point), as presented in Extended Data Table 1b. B, BC and
$\mathrm{T}$ stand for base, base common and top, respectively. Blue-shaded regions represent depth intervals for which sedimentation rates (blue lines) were calculated. The hiatus of $\sim 1.5 \mathrm{Myr}$ in Core 35 is indicated as a red curly line. Epochs and ages are expressed in Myr ago (Ma), following GTS2012. 

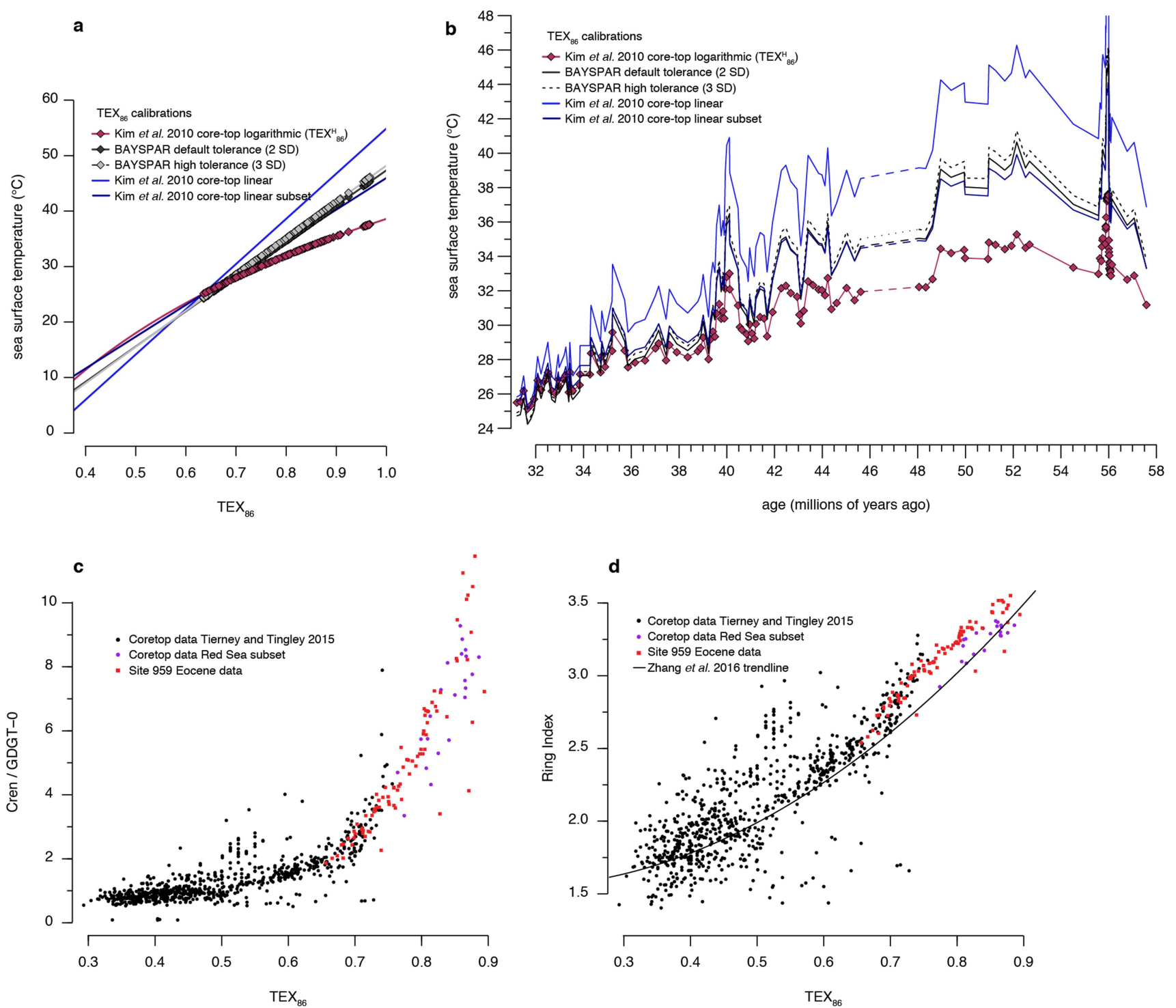

Extended Data Fig. 2 | Comparison between different TEX 86-to-SST calibrations and different GDGT ratios. a, $\mathrm{TEX}_{86}-\mathrm{SST}$ calibration lines (trend lines for BAYSPAR) for one logarithmic and several linear calibrations. Plotted symbols are the Site $959 \mathrm{TEX}_{86}$ record, to illustrate which part of the calibration is relevant for this study. Compared calibrations are: BAYSPAR ${ }^{19,41}$ with default settings (search tolerance for 2 $\mathrm{TEX}_{86}$ standard deviations, 0.13; dark-grey line, dark-grey diamonds), BAYSPAR with increased search tolerance (0.2) (dashed line, light-grey diamonds), Kim et al. ${ }^{18}$ logarithmic $\mathrm{TEX}_{86}^{\mathrm{H}}$ core-top calibration (red line, red diamonds), linear core-top calibration ${ }^{18}$ (light-blue line) and linear subset core-top calibration without Red Sea and polar ocean data ${ }^{18}$ (dark-

blue line). It is of note that the logarithmic $\mathrm{TEX}_{86}^{\mathrm{H}}$ starts strongly diverging from the linear BAYSPAR and subset calibrations from $\mathrm{TEX}_{86}$ values of $>0.8$. b. Site 959 SST record using different $\mathrm{TEX}_{86}$ calibrations.

Calibrations and line colours and types are as in a. c, Ratio of crenarchaeol to GDGT-0 against TEX ${ }_{86}$. Data are from a core-top compilation ${ }^{41}$ (black circles; Red Sea subset, purple circles) and our Site 959 record (red squares). d, Ring index sensu Zhang et al..$^{50}$ against $\mathrm{TEX}_{86}$. Data are from a core-top compilation (black circles; Red Sea subset, purple circles) and our Site 959 record (red squares). The exponential regression line of Zhang et al. through the core-top data is plotted as a black line. 

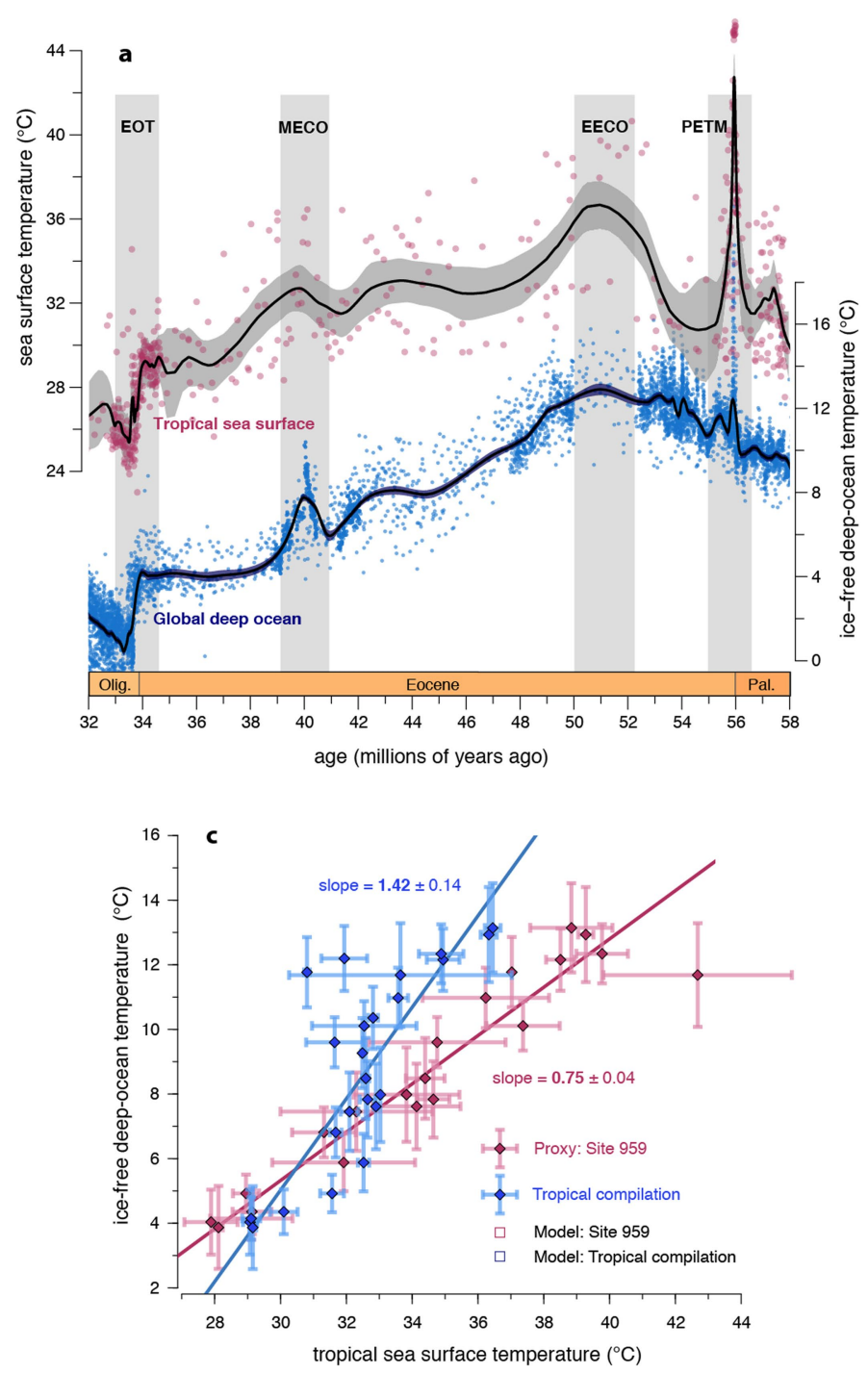

Extended Data Fig. 3 | Sensitivity of main results to TEX $_{86}$ calibration. a, Top, tropical SST compilation. Proxy data are compiled as described in Methods (red symbols), with all $\mathrm{TEX}_{86}$-based records converted to SST using the BAYSPAR calibration (default settings, search tolerance as described in Methods). The fitted LOESS model is plotted as a black line, with the $95 \%$ confidence interval as grey shading. Bottom, ice-free deepocean temperature compilation. $\delta^{18} \mathrm{O}$-based proxy data are compiled as described in Methods. The fitted LOESS model is plotted as a black line and the $95 \%$ confidence interval as dark blue shading. $\mathbf{b}$, Calculated MTG based on LOESS fits of proxy data (lines, propagated 95\% confidence intervals shown as shading). The black line with the grey silhouette shows the tropical compilation with $\operatorname{TEX}_{86}^{\mathrm{H}}$ calibration and the blue line with the b

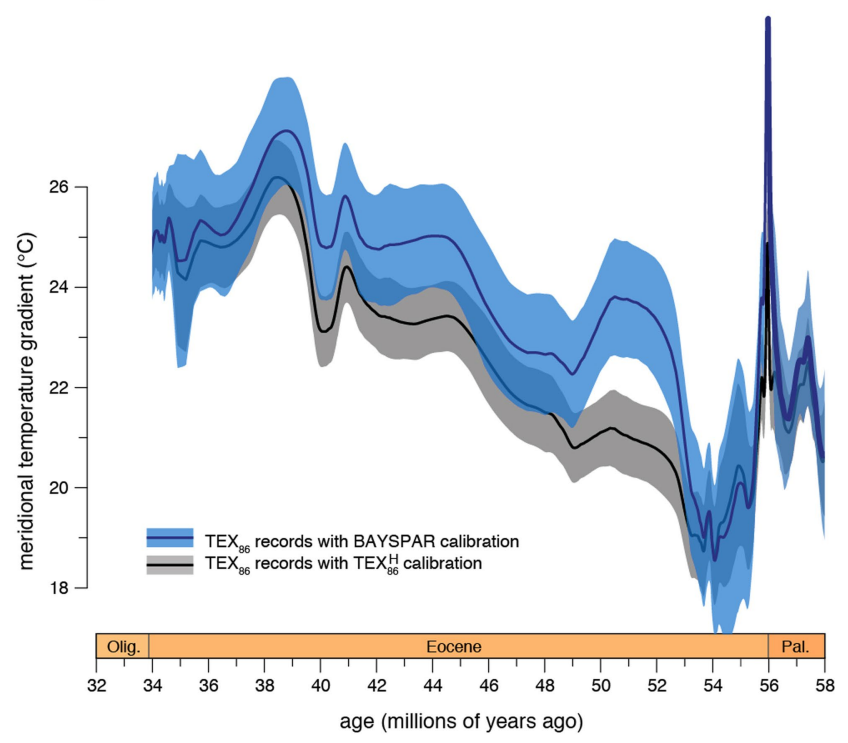

blue silhouette shows the BAYSPAR calibration. c, Proxy (blue diamonds, tropical compilation; red diamonds, Site 959) deep-ocean temperature against tropical SST using the BAYSPAR calibration for $\mathrm{TEX}_{86}$-based records. Lines represent Deming regression analysis through proxy data. The slope (polar amplification factor) is $1.42 \pm 0.14$ ( \pm 1 standard error) for the tropical compilation and $0.75 \pm 0.04$ for Site 959. Proxy data grouped into 1-Myr bins from 34-58 Myr ago, with error bars representing one standard deviation due to binning. This sensitivity analysis shows that calculated MTGs and the constant polar amplification factor are relatively robust to the specific $\mathrm{TEX}_{86}$ calibration used, although MTGs are less reduced in the early Eocene when using the BAYSPAR calibration. Polar amplification factors are lower, but reflect a linear relationship. 
a

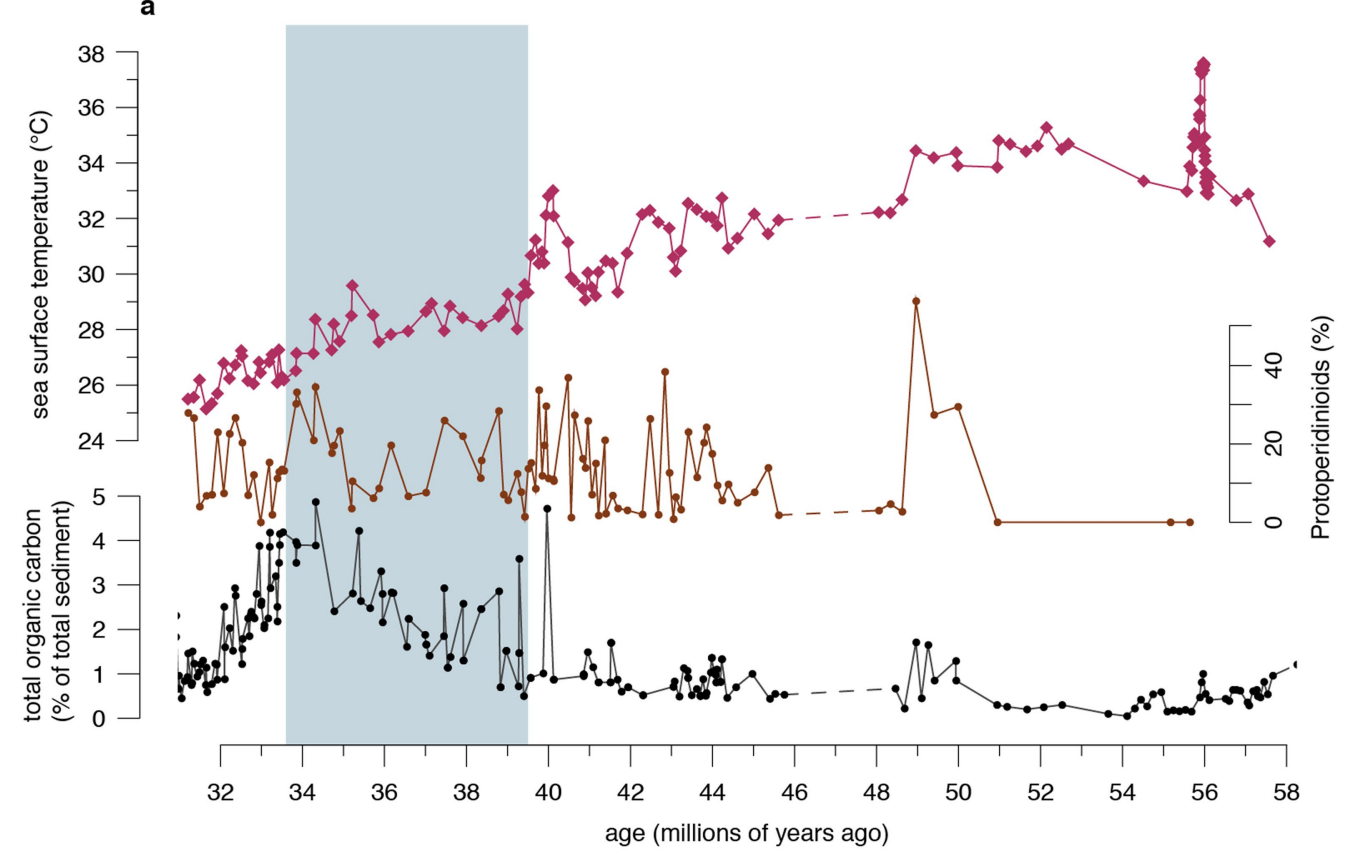

b

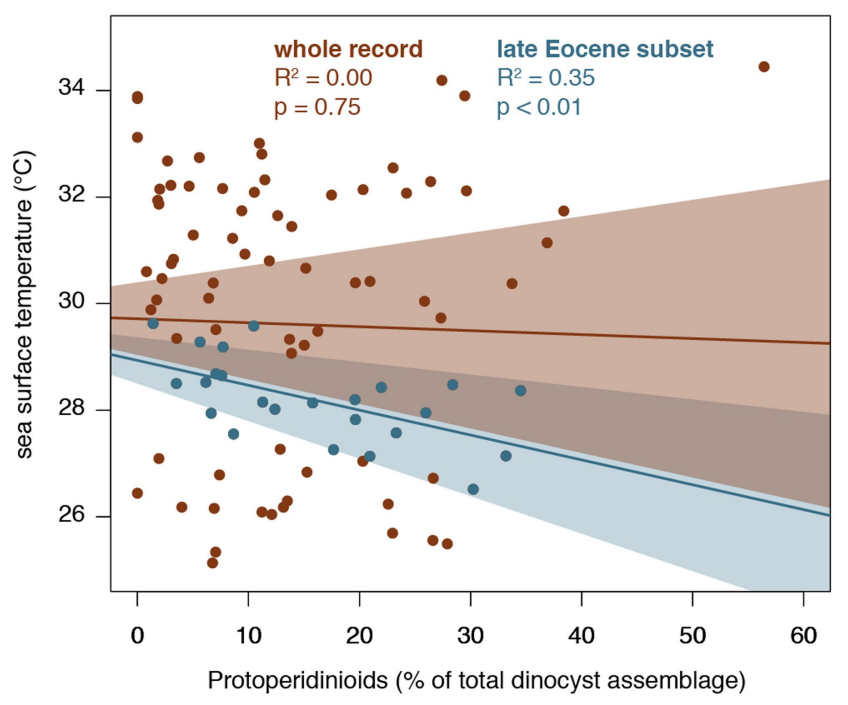

Extended Data Fig. 4 Regression analysis between reconstructed SST and abundance of upwelling indicators. a, TEX $\mathrm{H}_{86}^{\mathrm{H}}$-based SST (red diamonds, upper left vertical axis), protoperidinioid abundance (percentage of total dinocyst assemblage; brown dots, right vertical axis) and TOC (percentage of sediment; black dots, lower left vertical axis) records of ODP Site 959. Dashed lines represent a hiatus in Site 959. Age is in GTS2012. b, Regression analysis between SST and percentage of protoperidinioid dinocysts of total dinocyst assemblage, showing a nonsignificant relationship with a very low fit (brown line, 90\% confidence

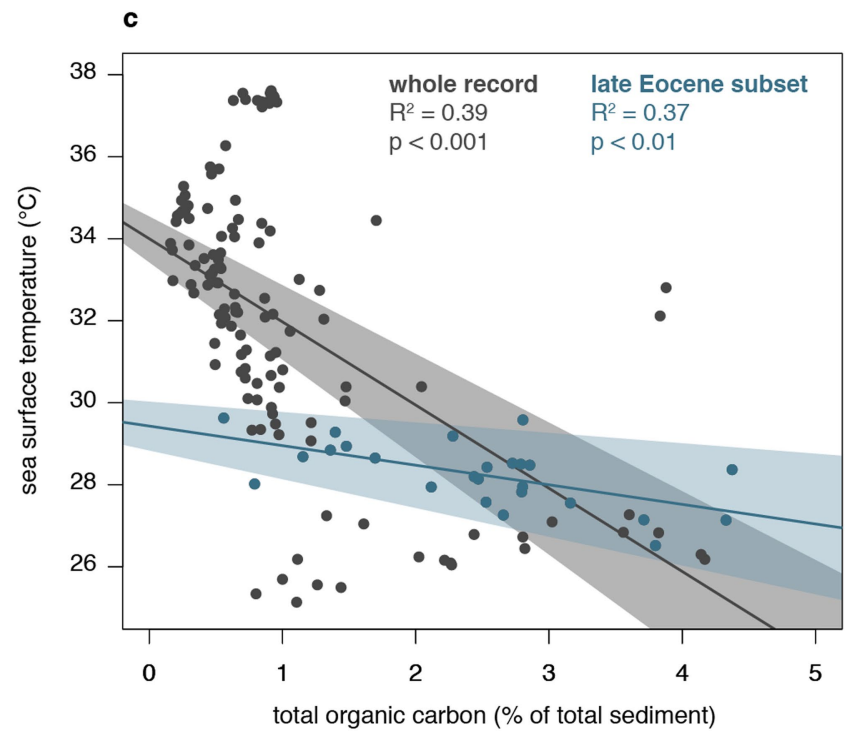

interval shown as brown shading; $\left.R^{2}=0.00, P=0.75\right)$ and a better fit $\left(R^{2}=0.35\right)$ that is significant $(P<0.01)$ when only the late Eocene (postMECO) part of the record is considered (blue-grey line; $90 \%$ confidence interval is shown as blue-grey shading). c, Regression analysis between SST and percentage of TOC in sediment, showing a significant negative correlation for the whole record $\left(R^{2}=0.39, P<0.001\right.$; dark-grey line, with the $90 \%$ confidence interval shown as dark-grey shading) and the late Eocene subset $\left(R^{2}=0.37, P<0.01\right.$; blue-grey line, with the $90 \%$ confidence interval shown as blue-grey shading). 


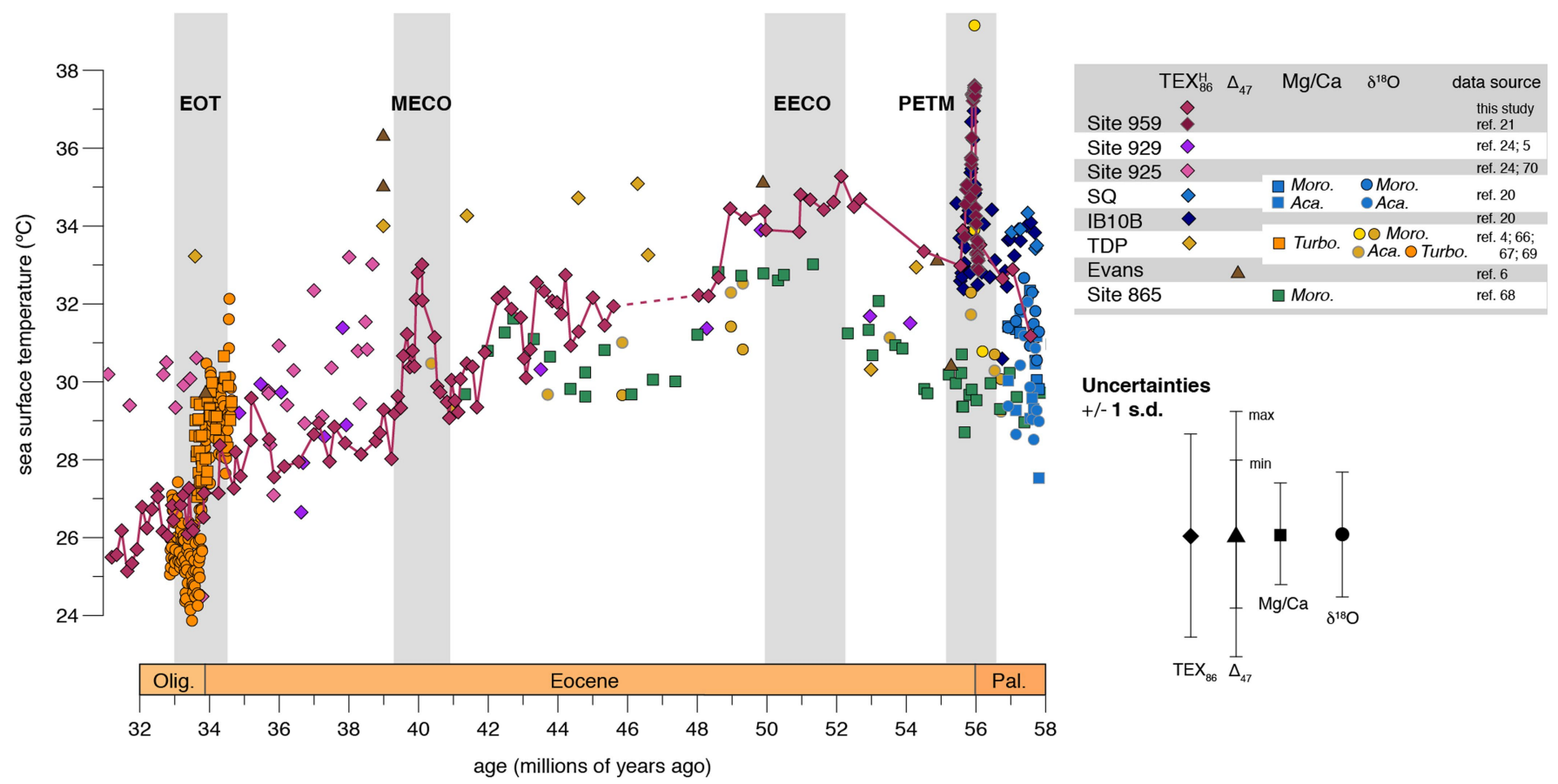

Extended Data Fig. 5 | Eocene multi-proxy tropical SST compilation. Compilation presented in Fig. 2, here plotted per site and proxy, with data sources in the key. The abbreviations Moro., Aca., and Turbo. stand for foraminifera genera Morozovella, Acarinina and Turborotalia, respectively. The dashed line in the Site 959 record represents a hiatus. Conservative estimates of propagated calibration and analytical errors (1 s.d.) are $\pm 2.6^{\circ} \mathrm{C}$ for $\mathrm{TEX}_{86}^{\mathrm{H}}, \pm 1.6^{\circ} \mathrm{C}$ for $\delta^{18} \mathrm{O}$ and $\pm 1.3^{\circ} \mathrm{C}$ for $\mathrm{Mg} / \mathrm{Ca} . \Delta_{47}$ uncertainties are as reported in the original study ${ }^{6}$, with the minimum and maximum per-sample uncertainty. Uncertainties are plotted on the same relative vertical temperature scale as the data to facilitate comparison. The age is in Myr ago, following GTS2012. 


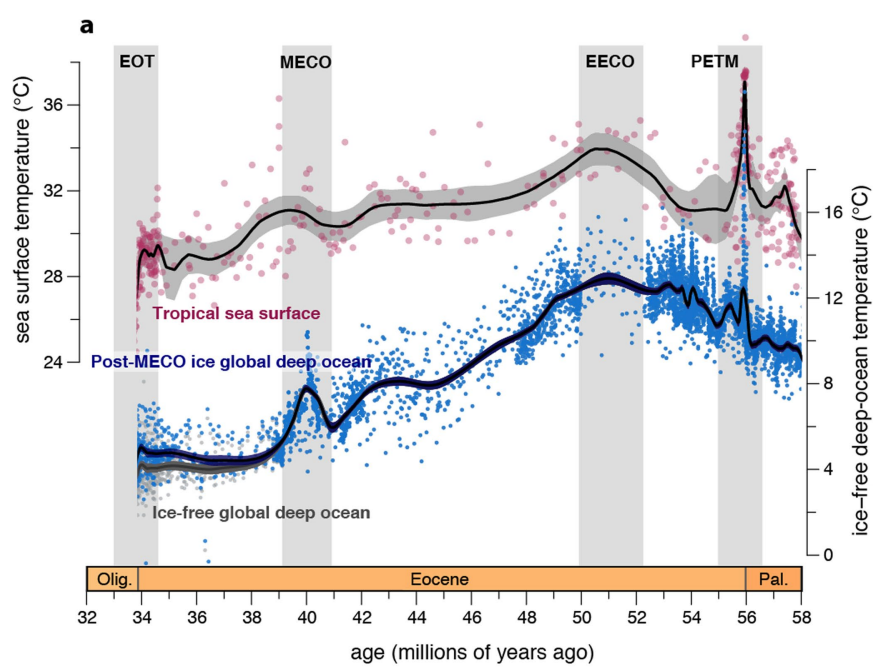

b
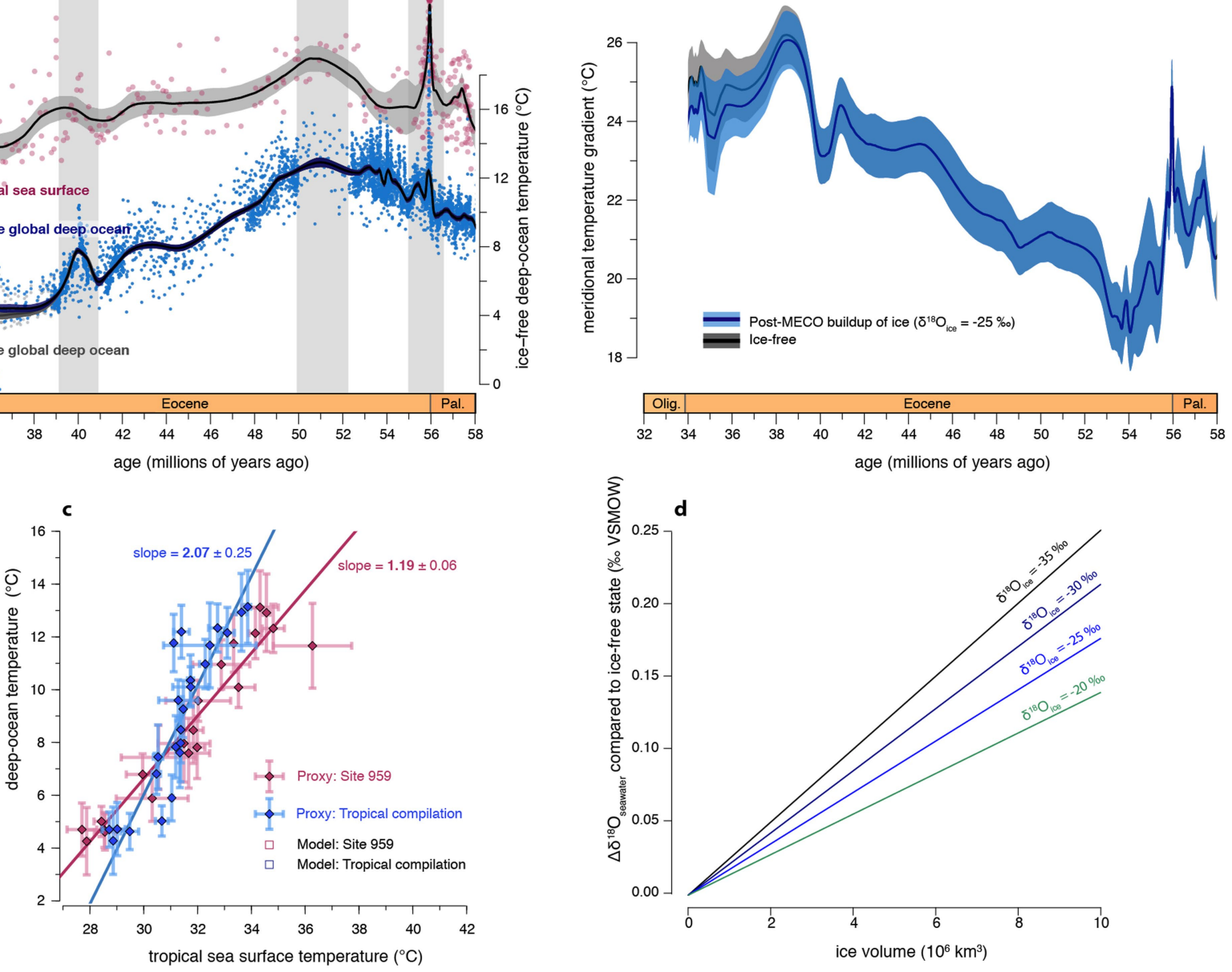

Extended Data Fig. 6 | Sensitivity of main results to late Eocene ice volume. a, Top, tropical SST compilation; proxy data are compiled as described in Methods (red symbols). The fitted LOESS model is plotted as a black line and the $95 \%$ confidence interval as grey shading. Bottom, deep-ocean temperature compilation; $\delta^{18} \mathrm{O}$-based proxy data are compiled as described in Methods. Ice-free deep-ocean temperatures and fitted LOESS model are shown as grey dots and line, respectively, and the deepocean temperature compilation and fitted LOESS model including late Eocene ice volume effect (Methods) as blue dots and line, correspondingly. 95\% LOESS confidence intervals are shown as shading. b. Calculated MTG based on LOESS fits of proxy data (lines; propagated 95\% confidence intervals are shown as silhouettes). The black line with grey silhouette

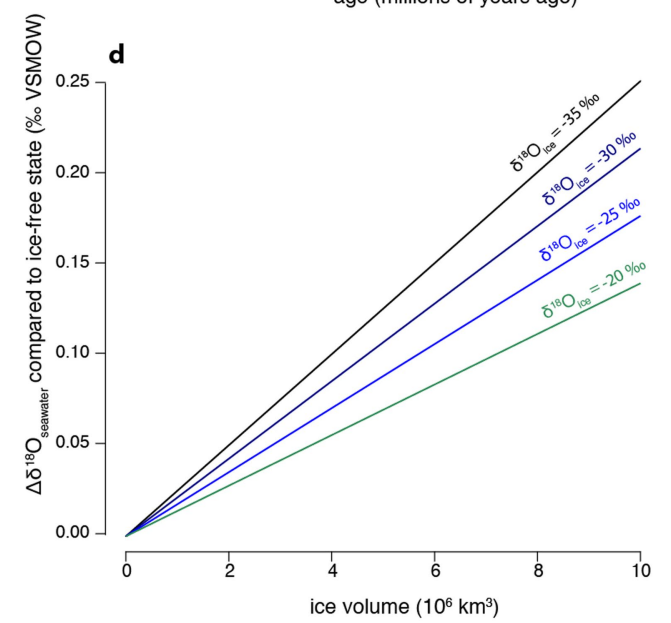

shows results obtained using ice-free deep-ocean temperatures, and the blue line with blue silhouette includes the late Eocene ice volume effect on the deep-ocean temperature. c, Proxy (blue diamonds, tropical compilation; red diamonds, Site 959) deep-ocean temperature, including the late Eocene ice volume effect, against tropical SST. Lines represent Deming regression analysis through proxy data. The slope (polar amplification factor) is $2.07 \pm 0.25$ ( \pm 1 standard error) for the tropical compilation and $1.19 \pm 0.06$ for Site 959). Proxy data grouped into 1-Myr bins from 34-58 Myr ago, with error bars representing one standard deviation due to binning. d, Sensitivity of $\delta^{18} \mathrm{O}$ of Eocene seawater (\% VSMOW) to the build-up of $0-10^{7} \mathrm{~km}^{3}$ of ice with varying isotopic composition. 


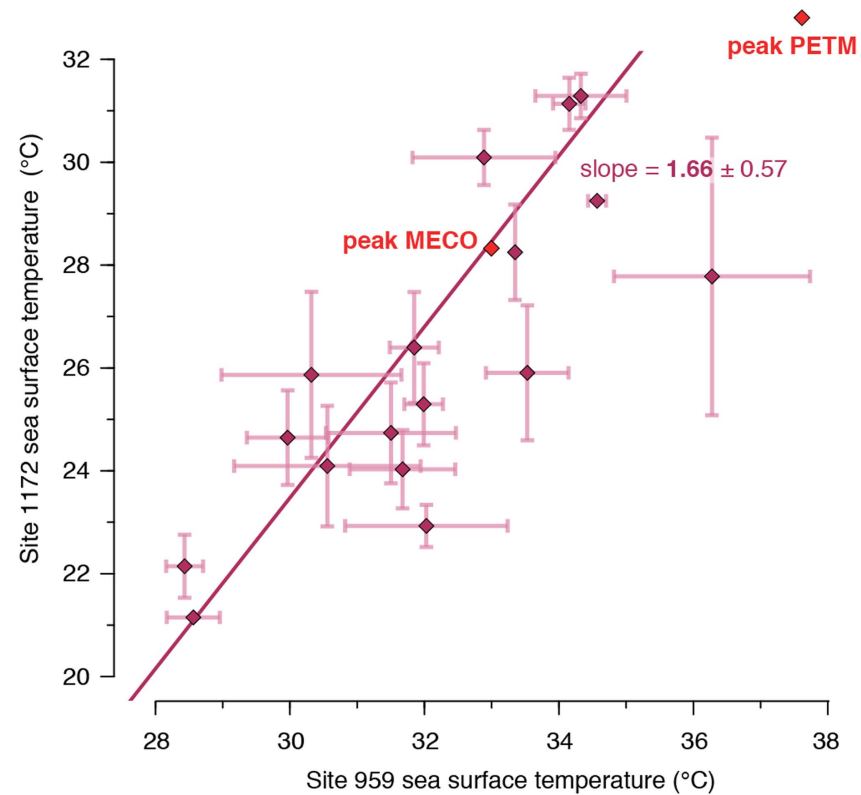

Extended Data Fig. 7 | Linear relationship between high-latitude and tropical SST. Site 1172 TEX $_{86}$-based SST (record plotted in Fig. 2) against Site $959 \mathrm{TEX}_{86}$-based SST. Lines represent Deming regression analysis through proxy data (polar amplification factor, $1.66 \pm 0.57$ ). Proxy data are grouped into 1-Myr bins from 34-58 Myr ago, with error bars representing one standard deviation due to binning. Peak PETM and peak MECO SSTs are plotted as separate points, which fall within the uncertainty of the regression line. 

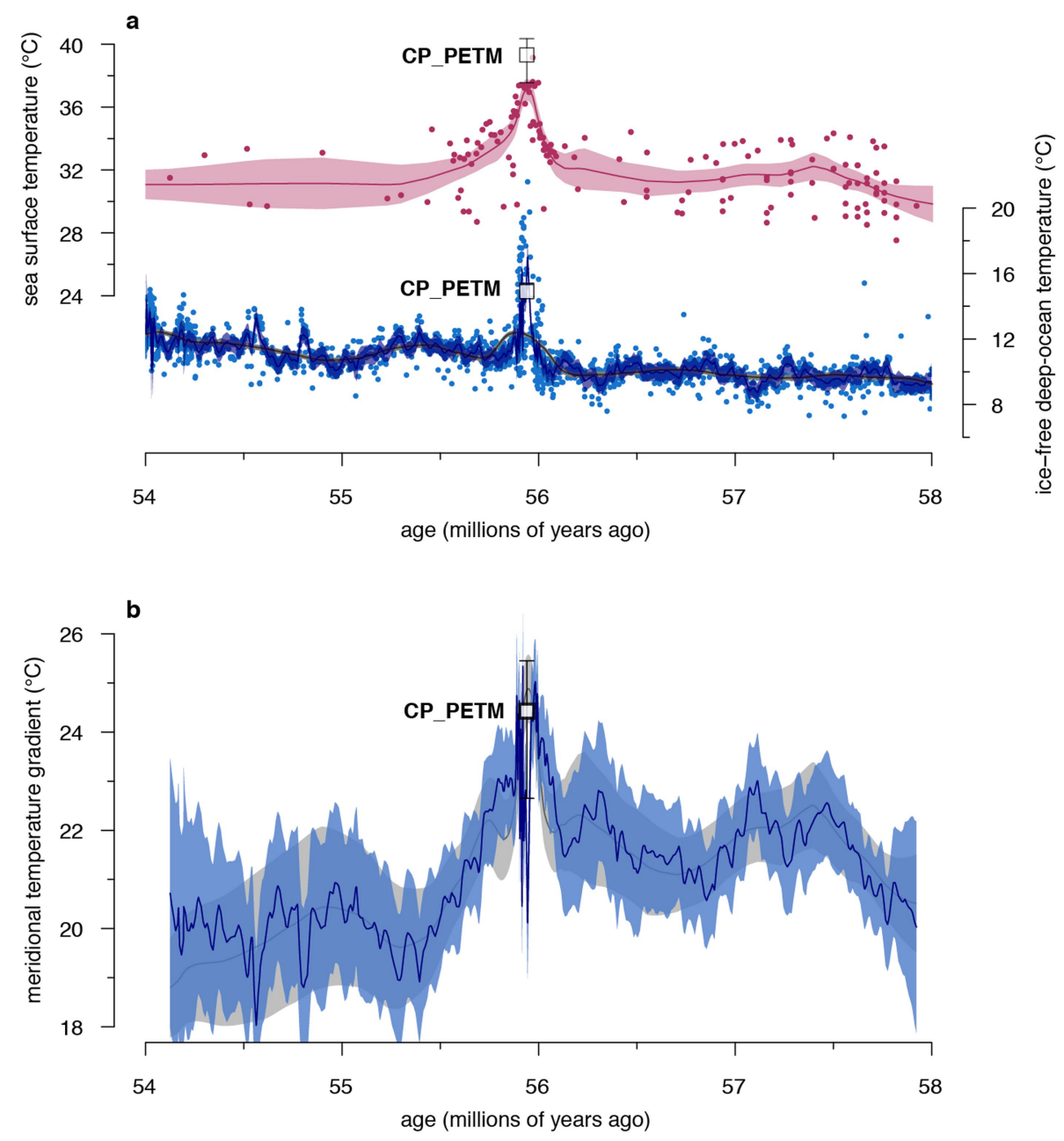

Extended Data Fig. 8 | PETM temperature gradient proxy-model comparison. a, Top, tropical SST compilation; proxy data are compiled as described in Methods (red symbols). The fitted LOESS model is plotted as a red line, with the $95 \%$ confidence interval as pink shading. Bottom, ice-free deep-ocean temperature compilation; $\delta^{18} \mathrm{O}$-based proxy data are compiled as described in Methods. Generalized cross-validation (GCV)optimized fitted LOESS model (as in Fig. 3) plotted as grey line, with the $95 \%$ confidence interval as grey shading. An alternative LOESS model with small bandwidth ( 0.25 times the GCV-optimized span) that tracks deepocean PETM temperature more closely is shown as the blue line, with the $95 \%$ confidence interval as blue shading. Data are plotted together with the PETM simulation of Kiehl and Shield ${ }^{28}$ (black open squares, seasonal range error bars) with altered cloud parameters (CP_PETM). b, Calculated MTG based on LOESS fits of proxy data and of the model simulation CP_PETM. The grey line is obtained using a GCV-optimized fitted LOESS model and the blue line using a smaller-bandwidth deep-ocean LOESS model (propagated $95 \%$ confidence intervals are shown as shading). We note that the PETM MTG pattern is complex owing to its sensitivity to the specific records, age models and filtering used, and might have evolved over the course of the event. Nevertheless, peak PETM MTG matches the simulation CP_PETM poorly. The age is in Myr ago, following GTS2012. 


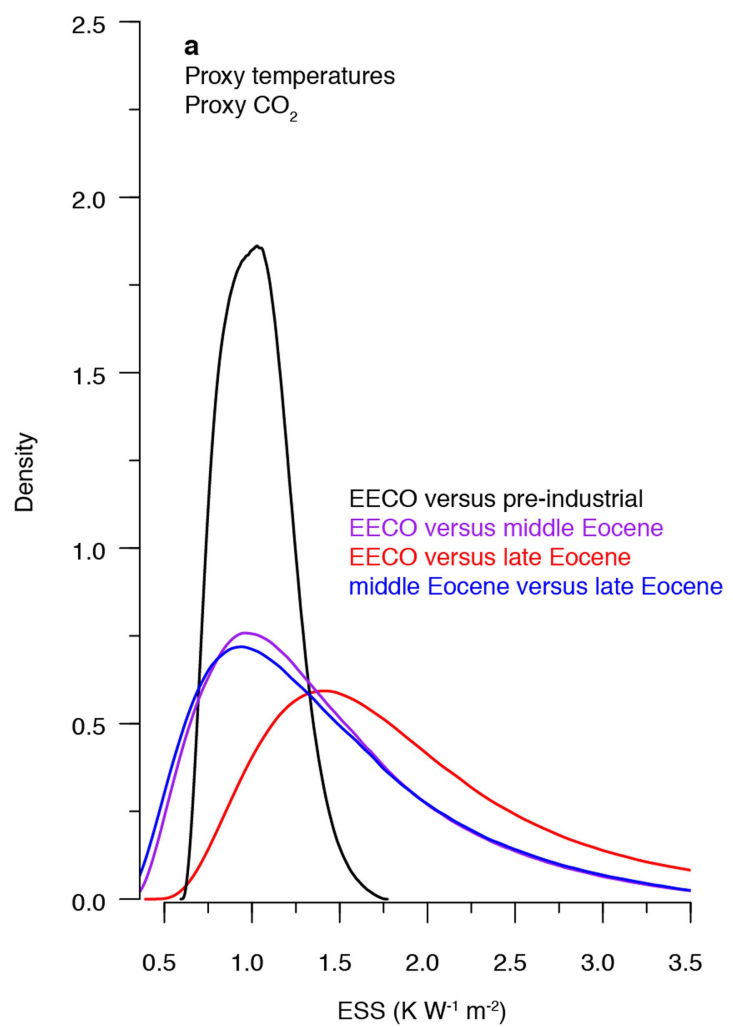

Extended Data Fig. 9 | Probability distributions of Eocene Earth system sensitivity. a, b, ESS estimates using proxy (a) and model (b) temperatures in combination with proxy-based $\mathrm{CO}_{2}$ concentrations, derived as described in Methods. Eocene ESS is separated into the late Eocene relative to the EECO (red), the middle Eocene relative to the EECO (purple) and

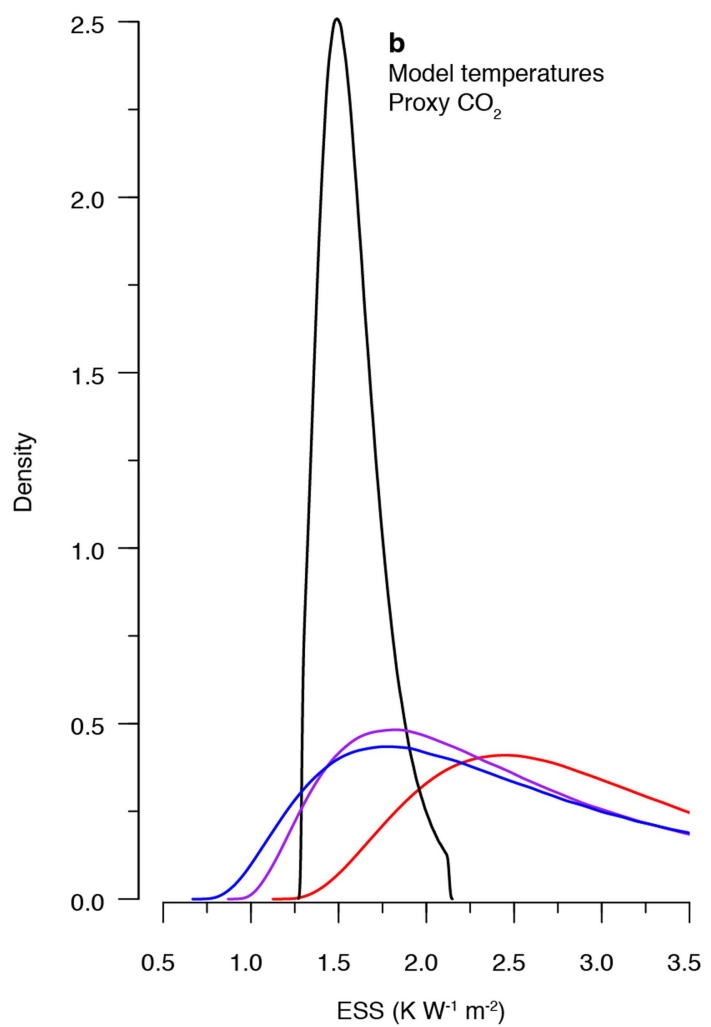

the middle Eocene relative to late Eocene (blue). ESS estimates of the EECO relative to preindustrial temperature (black) have lower error owing to the high precision of preindustrial $\mathrm{CO}_{2}$ concentration and temperature, but include additional long-term non- $\mathrm{CO}_{2}$ effects. 


\section{RESEARCH LETTER}

Extended Data Table 1 | Palaeolatitude and age constraints of Site 959 over the Eocene

a

\begin{tabular}{|l|l|l|}
\hline Palaeolatitude at & Matthews et al. 2016 & \multicolumn{1}{l|}{ Torsvik et al. 2012 } \\
\hline $60 \mathrm{Ma}$ & $0.982^{\circ} \mathrm{N}$ & $9.826^{\circ} \mathrm{S}$ \\
\hline $55 \mathrm{Ma}$ & $0.779^{\circ} \mathrm{N}$ & $9.480^{\circ} \mathrm{S}$ \\
\hline $50 \mathrm{Ma}$ & $0.581^{\circ} \mathrm{N}$ & $9.130^{\circ} \mathrm{S}$ \\
\hline $45 \mathrm{Ma}$ & $0.587^{\circ} \mathrm{N}$ & $7.405^{\circ} \mathrm{S}$ \\
\hline $40 \mathrm{Ma}$ & $0.600^{\circ} \mathrm{N}$ & $5.674^{\circ} \mathrm{S}$ \\
\hline $35 \mathrm{Ma}$ & $0.942^{\circ} \mathrm{N}$ & $4.568^{\circ} \mathrm{S}$ \\
\hline $30 \mathrm{Ma}$ & $1.291^{\circ} \mathrm{N}$ & $3.462^{\circ} \mathrm{S}$ \\
\hline
\end{tabular}

b

\begin{tabular}{|c|c|c|c|c|c|c|c|}
\hline Event & Species / Proxy & $\begin{array}{l}\text { Minimum } \\
\text { depth (mbsf) }\end{array}$ & $\begin{array}{l}\text { Maximum } \\
\text { depth (mbsf) }\end{array}$ & $\begin{array}{l}\text { Mean depth } \\
\text { (mbsf) }\end{array}$ & $\begin{array}{l}\text { One- } \\
\text { sided } \\
\text { error }(m)\end{array}$ & $\begin{array}{l}\text { Age } \\
\text { GTS2012 }\end{array}$ & Reference \\
\hline $\begin{array}{l}\text { Latest Eocene Os } \\
\text { isotope minimum }\end{array}$ & ${ }^{187}$ Os $/{ }^{188}$ Os & 448.00 & 469.30 & 458.65 & 10.65 & 34.40 & $\begin{array}{l}\text { Ravizza and Paquay } \\
2008\left({ }^{58}\right)\end{array}$ \\
\hline $\begin{array}{l}\text { MECO Os isotope } \\
\text { minimum }\end{array}$ & ${ }^{187}$ Os $/{ }^{188}$ Os & 576.05 & 581.51 & 578.78 & 2.73 & 40.02 & $\begin{array}{l}\text { van der Ploeg et al. in } \\
\text { press }\left({ }^{60}\right)\end{array}$ \\
\hline Base & $\begin{array}{l}\text { Reticulofenestra } \\
\text { umbilicus }\end{array}$ & 652.12 & 655.34 & 653.73 & 1.61 & 42.84 & $\begin{array}{l}\text { Shafik et al. } 1998\left({ }^{55}\right) \text {; this } \\
\text { study }\end{array}$ \\
\hline Base & $\begin{array}{l}\text { Sphenolithus } \\
\text { furcatolithoides morph. B }\end{array}$ & 671.56 & 673.10 & 672.33 & 0.77 & 43.55 & This study \\
\hline Base common & Sphenolithus cuniculus & 701.38 & 702.12 & 701.75 & 0.37 & 44.33 & $\begin{array}{l}\text { Shafik et al. 1998; this } \\
\text { study }\end{array}$ \\
\hline Base & $\begin{array}{l}\text { Sphenolithus } \\
\text { furcatolithoides morph. A }\end{array}$ & 731.73 & 732.49 & 732.11 & 0.38 & 45.63 & This study \\
\hline Base & Nannotetrina alata group & 740.95 & 741.63 & 741.29 & 0.34 & 46.55 & $\begin{array}{l}\text { Shafik et al. 1998; this } \\
\text { study }\end{array}$ \\
\hline Bot hiatus & - & 740.95 & 741.63 & 741.29 & 0.34 & 48.03 & This study \\
\hline Top & Discoaster lodoensis & 746.73 & 747.45 & 747.09 & 0.36 & 48.36 & This study \\
\hline Base & Discoaster sublodoensis & 755.06 & 755.80 & 755.43 & 0.37 & 49.01 & $\begin{array}{l}\text { Shafik et al. 1998; this } \\
\text { study }\end{array}$ \\
\hline Top & Tribrachiatus orthostylus & 774.49 & 775.86 & 775.18 & 0.69 & 51.05 & This study \\
\hline Top & Tribrachiatus contortus & 784.05 & 787.03 & 785.54 & 1.49 & 54.17 & Shafik et al. 1998 \\
\hline $\begin{array}{l}\text { Onset PETM } \\
\text { isotope excursion }\end{array}$ & $\delta^{13} \mathrm{C}$ & 804.08 & 804.10 & 804.09 & 0.01 & 56.00 & Frieling et al. $2018\left(\left(^{21}\right)\right.$ \\
\hline Base & Discoaster multiradiatus & 821.92 & 823.26 & 822.59 & 0.67 & 57.10 & Shafik et al. 1998 \\
\hline
\end{tabular}

a, Palaeolatitudes reconstructed with GPlates using the hotspot reference frame of Matthews et al. ${ }^{30}$ and the palaeomagnetic reference of Torsvik et al. ${ }^{100}$. Present latitude is $3.6276^{\circ} \mathrm{N}$ and longitude is $2.7352^{\circ} \mathrm{W}$. b. Bio- and chemostratigraphic age-depth tiepoints (from refs $21,55,58,60$ and this work) used in developing the age model for the Eocene of Site 959 . 